\title{
Role of Tin+ and Aln+ ion irradiation $(n=1,2)$ during Ti1-xAlxN alloy film growth in a hybrid HIPIMS/magnetron mode
}

\author{
Grzegorz Greczynski, Jun Lu, M.P. Johansson, Jens Jensen, Ivan Petrov, \\ Joseph E Greene and Lars Hultman
}

\section{Linköping University Post Print}

N.B.: When citing this work, cite the original article.

Original Publication:

Grzegorz Greczynski, Jun Lu, M.P. Johansson, Jens Jensen, Ivan Petrov, Joseph E Greene and Lars Hultman, Role of Tin+ and Aln+ ion irradiation $(n=1,2)$ during Ti1-xAlxN alloy film growth in a hybrid HIPIMS/magnetron mode, 2012, Surface \&amp; Coatings Technology, (206), 19-20, 4202-4211.

http://dx.doi.org/10.1016/j.surfcoat.2012.04.024

Copyright: Elsevier

http://www.elsevier.com/

Postprint available at: Linköping University Electronic Press http://urn.kb.se/resolve?urn=urn:nbn:se:liu:diva-79709 


\title{
Role of $\mathrm{Ti}^{n+}$ and $\mathrm{Al}^{n+}$ ion irradiation $(n=1,2)$ during $\mathrm{Ti}_{1-x} \mathrm{Al}_{x} \mathrm{~N}$ alloy film growth in a hybrid HIPIMS/magnetron mode
}

\author{
G. Greczynski ${ }^{1}$, J. Lu ${ }^{1}$, M.P. Johansson ${ }^{1}$, J. Jensen ${ }^{1}$, I. Petrov ${ }^{1,2}$, J.E. Greene ${ }^{1,2}$, and L. Hultman ${ }^{1}$ \\ ${ }^{1}$ Department of Physics (IFM), Linköping University, SE-581 83 Linköping, Sweden \\ ${ }^{2}$ Frederick Seitz Materials Research Laboratory, University of Illinois, Urbana, Illinois 61801 \\ and Materials Science Department, University of Illinois, Urbana, Illinois 61801
}

\begin{abstract}
Metastable $\mathrm{Ti}_{1-x} \mathrm{Al}_{x} \mathrm{~N}(0.4 \leq x \leq 0.76)$ films are grown using a hybrid approach in which high-power pulsed magnetron sputtering (HIPIMS) is combined with dc magnetron sputtering (DCMS). Elemental Al and Ti metal targets are co-sputtered with one operated in HIPIMS mode and the other target in DCMS; the positions of the targets are then switched for the next set of experiments. In both cases, the AlN concentration in the co-sputtered films, deposited at $T_{s}=500$ ${ }^{\circ} \mathrm{C}$ with $R=1.5-5.3 \AA / \mathrm{s}$, is controlled by adjusting the average DCMS target power. Resulting films are analyzed by x-ray diffraction, scanning electron microscopy, transmission electron microscopy, atomic force microscopy, elastic recoil detection analysis, and nanoindentation. Mass spectroscopy is used to determine ion energy distribution functions at the substrate. The distinctly different flux distributions obtained from targets driven in HIPIMS vs. DCMS modes allow the effects of $\mathrm{Al}^{n+}$ and $\mathrm{Ti}^{n+}(n=1,2)$ ion irradiation on film growth kinetics, and resulting properties, to be investigated separately. Bombardment with $\mathrm{Al}^{n+}$ ions (primarily $\mathrm{Al}^{+}$in the $\mathrm{Al}$ HIPIMS/Ti-DCMS configuration) during film growth leads to NaCl-structure $\mathrm{Ti}_{1-x} \mathrm{Al}_{x} \mathrm{~N}(0.53 \leq x$ $\leq 0.60)$ films which exhibit high hardness (> $30 \mathrm{GPa})$ with low stress (0.2 - 0.7 GPa tensile). In contrast, films with corresponding $\mathrm{AlN}$ concentrations grown under $\mathrm{Ti}^{n+}$ metal ion irradiation (with a significant $\mathrm{Ti}^{2+}$ component) in the Ti-HIPIMS/Al-DCMS mode have much lower hardness, 18-19 GPa, and high compressive stress ranging up to $2.7 \mathrm{GPa}$. The surprisingly large variation in mechanical properties results from the fact that the kinetic AlN solubility limit $x_{\max }$ in
\end{abstract}


$\mathrm{Ti}_{1-x} \mathrm{Al}_{x} \mathrm{~N}$ depends strongly on, in addition to $T_{s}$ and $R$, the target power configuration during growth and hence the composition of the ion flux. AlN with $x_{\max } \sim 64$ mol\% can be accommodated in the $\mathrm{NaCl}$ structure under $\mathrm{Al}^{n+}$ ion flux, compared with $\sim 40$ mol\% for growth with $\mathrm{Ti}^{n+}$ flux. The strong asymmetry in film growth reaction paths is due primarily to the fact that the doubly-ionized metal ion flux is approximately two orders of magnitude higher from the Ti target, than from Al, powered with HIPIMS. This asymmetry becomes decisive upon application of a moderate substrate bias voltage, $-60 \mathrm{~V}$, applied synchronously with HIPIMS pulses, during growth.

Keywords: HIPIMS; HPPMS; TiAlN; ionized PVD 


\section{Introduction}

Thin films of metastable NaCl-structure $\mathrm{Ti}_{1-x} \mathrm{Al}_{x} \mathrm{~N}$ exhibiting high hardness (typically 30 GPa) and good high-temperature oxidation resistance are used for wear protection in a wide variety of applications ranging from cutting tools to mechanical components in the aerospace industry. ${ }^{1}$ Enhanced performance is obtained at elevated temperatures for alloy films with high AlN content. However, kinetic solid solubilities of wurtzite-structure AlN in cubic TiN have been shown to depend sensitively on film growth parameters. ${ }^{2}$ At thermodynamic equilibrium, the solubility of AlN in TiN is low, only $2 \mathrm{~mol} \%$ at $1000{ }^{\circ} \mathrm{C}{ }^{3}$ and $5 \mathrm{~mol} \%$ at $2425{ }^{\circ} \mathrm{C} .{ }^{4}$ The calculated $\mathrm{Ti}_{1-x} \mathrm{Al}_{x} \mathrm{~N}$ enthalpy of mixing is positive over the entire range of composition and reaches a maximum (corresponding to the largest driving force for decomposition) at $x=0.68 .^{5}$ Nevertheless, metastable $\mathrm{NaCl}$-structure alloys can be obtained by physical vapor deposition due to kinetically-limited low-temperature growth and dynamic low-energy ion-irradiation-induced mixing in the near-surface region. In conventional dc magnetron sputter (DCMS) deposition, reported kinetic $\mathrm{AlN}$ solubility limits in cubic $\mathrm{Ti}_{1-x} \mathrm{Al}_{x} \mathrm{~N}$ alloys are typically $x_{\max } \sim 0.50$ at film growth temperatures $T_{s}=500{ }^{\circ} \mathrm{C},{ }^{6,7}$ while $x_{\max }$ values up to 0.66 have been reported using cathodic arc evaporation. ${ }^{8,9}$ However, the resulting films have very high compressive stresses ranging up to -5 GPa (ref. 10) for DCMS and -9.1 GPa (ref. 11) for arc-deposited films.

It has been demonstrated previously that both the energy $E_{i}$ and the ion-to-metal flux ratio $J_{i} / J_{M e}$ incident at the growing film significantly affect film microstructure and physical properties of $\mathrm{T}_{0.5} \mathrm{Al}_{0.5} \mathrm{~N}$ alloys grown by DCMS. ${ }^{12}$ Low $E_{i}(\leq 20 \mathrm{eV})$ with high $J_{i} / J_{M e}$ values $(\geq 5.2)$ lead to film densification, larger grain size, and low residual stress. In contrast, films grown with the same total kinetic energy at the substrate, but with high values of $E_{i}(\geq 100 \mathrm{eV})$ and $J_{i} / J_{M e} \sim 1$ result in excess $\mathrm{N}$ incorporation, residual point defect concentrations, decreased average column widths, high compressive stresses, and precipitation of second-phase wurtzite-structure AlN. ${ }^{13} \mathrm{~A}$ 
potentially attractive and unique feature of high-power pulsed magnetron sputtering (HIPIMS) ${ }^{14}$ is the ability to ionize up to $90 \%$ of the sputtered metal flux ${ }^{15}$ depending upon the metal. Thus, HIPIMS offers the opportunity to increase momentum transfer to the growing film, while providing enhanced adatom mobilities and higher probabilities for overcoming Ehrlich step-edge barriers, ${ }^{16,17,18,19}$ utilizing sputtered metal atoms which are ionized in the plasma. ${ }^{20}$

Here, we report results of an investigation of the growth of polycrystalline $\mathrm{Ti}_{1-x} \mathrm{Al}_{x} \mathrm{~N}$ films by co-sputtering from separate elemental metal targets, Al and Ti, in a hybrid HIPIMS/DCMS configuration in order to selectively control the composition of metal ion fluxes during ionassisted growth. Two independent sets of experiments are performed. In the first set, the Al target is powered with HIPIMS, while the Ti target is operated with DCMS. The positions of the targets are then switched for the second set of experiments. Thus, we separately probe the role of intense $\mathrm{Ti}^{n+}$ and $\mathrm{Al}^{n+}$ ion fluxes $(n=1,2)$ from HIPIMS-powered targets on film growth kinetics, microstructure, and physical properties over a wide range in metastable alloy compositions. In these experiments, we investigate the composition range $0.40 \leq x \leq 0.76$ in order to determine the effect of metal ion flux on AlN solubility in metastable NaCl-structure solid solutions.

We demonstrate that high-AlN-concentration $\mathrm{Ti}_{1-x} \mathrm{Al}_{x} \mathrm{~N}$ films, which exhibit both high hardness and low residual stress, can be successfully grown by tuning momentum transfer to the growing film. Simultaneous control of metal ion flux $J_{M e^{+}}$, energy $E_{i}$, and charge (1+vs. 2+) together play a determinant role in providing efficient ion-irradiation-induced near-surface mixing, while suppressing the chemical driving force for surface-induced spinodal decomposition. $^{2}$ 


\section{Experimental procedure}

All $\mathrm{Ti}_{1-x} \mathrm{Al}_{x} \mathrm{~N}$ films are grown in a CemeCon AG CC800/9 magnetron sputtering system ${ }^{21}$ with four cathodes, two of which can be operated in HIPIMS mode. The Ti and Al targets are cast rectangular plates with dimensions $88 \times 500 \mathrm{~mm}^{2}$. Si $(001)$ substrates, $30 \times 10 \mathrm{~mm}^{2}$, are positioned symmetrically with respect to the targets, which are tilted towards the substrate, resulting in a $21^{\circ}$ angle between the substrate normal and lines connecting the centers of the targets with the center of the substrate. The target-to-substrate distance is $180 \mathrm{~mm}$. Substrates are cleaned sequentially in acetone and isopropanol alcohol and mounted with clips such that their long sides are parallel to the long sides of the targets. The system base pressure is $<0.3 \mathrm{mPa}$ $\left(2.3 \times 10^{-6}\right.$ Torr $)$ and the total pressure $p_{\text {tot }}$ during deposition is $0.4 \mathrm{~Pa}$ ( 3 mTorr) with a $\mathrm{N}_{2} / \mathrm{Ar}$ flow ratio of 0.2 . The substrate temperature during deposition is $500{ }^{\circ} \mathrm{C}$. Substrate heating is accomplished using resistance heaters mounted symmetrically on the front and back sides of the vacuum chamber. Power to each heater is $10 \mathrm{~kW}$ during the $2 \mathrm{~h}$ heating phase and $8 \mathrm{~kW}$ during the $1.5 \mathrm{~h}$ depositions.

A hybrid powering scheme is employed in which one of the magnetron targets is operated in HIPIMS mode and the other is operated as a conventional dc magnetron. The AlN concentration in $\mathrm{Ti}_{1-x} \mathrm{Al}_{x} \mathrm{~N}$ films is controlled by varying the average power to the dc magnetron while maintaining the HIPIMS power constant. Two series of films are deposited. In the first set, the $\mathrm{Al}$ target is powered with HIPIMS and the Ti target is operated with DCMS (Al-HIPIMS/TiDCMS). The positions of the targets are then switched for the second set of experiments (TiHIPIMS/Al-DCMS). In the Al-HIPIMS/Ti-DCMS configuration, the average power to the Al HIPIMS target is $2.5 \mathrm{~kW}$ ( $5 \mathrm{~J} /$ pulse, $500 \mathrm{~Hz}, 10 \%$ duty cycle, limited by arcing in reactive mode), while the DCMS power $P_{d c}$ (Ti target) is varied from 1.4 to $4 \mathrm{~kW}$ resulting in AlN concentrations 
ranging from 40 to $76 \mathrm{~mol} \%$. For the second set of experiments, carried out in the Ti-HIPIMS/AlDCMS configuration, a higher average HIPIMS power, $5 \mathrm{~kW}(10 \mathrm{~J} /$ pulse, $500 \mathrm{~Hz}, 10 \%$ duty cycle), is necessary in order to obtain films in the desired composition range since the $\mathrm{Ti}$ sputtering rate is approximately half that of $\mathrm{Al}$. The $\mathrm{Al} P_{d c}$ is varied from $0.75 \mathrm{~kW}$ (resulting in $x$ $=0.41)$ to $2 \mathrm{~kW}(x=0.74)$. A pulsed substrate bias, $V_{s}=-60 \mathrm{~V}$, synchronized with the HIPIMS pulse, is applied in all experiments. Between HIPIMS pulses, the substrate is at floating potential, $V_{f} \sim-10 \mathrm{~V}$. Resulting film thicknesses are 0.81-2.86 $\mu \mathrm{m}$.

Mass spectroscopy (Hiden Analytical PSM003) is used to determine the composition and energy of ions incident at the growing film as a function of target power and configuration. In these experiments, the orifice of the mass spectrometer is placed parallel to, and $180 \mathrm{~mm}$ from, each target surface. The separation corresponds to the target/substrate distance during film growth. Ion-energy-distribution functions (IEDFs) are recorded in both DCMS and HIPIMS modes while sputtering one target $\left(\mathrm{Al}\right.$ or $\mathrm{Ti}$ ) at a time in $0.2: 1.0 \mathrm{~N}_{2}$ :Ar gas mixtures at $p_{\text {tot }}=0.4$ $\mathrm{Pa}\left(3 \mathrm{mT}\right.$ Torr). For the $\mathrm{Al}$ target, IEDFs are acquired for $\mathrm{Ar}^{+}, \mathrm{Ar}^{2+}, \mathrm{Al}^{+}, \mathrm{N}^{+}$, and $\mathrm{N}_{2}^{+}$ions in timeaveraged DCMS and time-resolved HIPIMS modes. Corresponding results for $\mathrm{Ar}^{+}, \mathrm{Ar}^{2+}, \mathrm{Ti}^{+}$, $\mathrm{Ti}^{2+}, \mathrm{N}^{+}$, and $\mathrm{N}_{2}^{+}$are obtained with the Ti target. Additional details of the IEDF measurements are given in Ref. 22.

Power levels applied to the HIPIMS targets during the mass spectroscopy experiments are the same as those used during film deposition $(2.5 \mathrm{~kW}$ for $\mathrm{Al}$ and $5 \mathrm{~kW}$ for Ti). For the DCMS experiments, average powers are used: $1.0 \mathrm{~kW}$ for $\mathrm{Al}$ (corresponding to $\mathrm{Ti}_{0.47} \mathrm{Al}_{0.53} \mathrm{~N}$ ) and $2.5 \mathrm{~kW}$ for $\mathrm{Ti}\left(\mathrm{Ti}_{0.44} \mathrm{Al}_{0.56} \mathrm{~N}\right)$. The HIPIMS data are obtained during the $\sim 20 \mu$ s window in which the target current densities reach their maximum values $\left(1.14 \mathrm{~A} / \mathrm{cm}^{2}\right.$ for $\mathrm{Ti}$ and $0.39 \mathrm{~A} / \mathrm{cm}^{2}$ for $\left.\mathrm{Al}\right)$. Average metal ion energies also attain maximum values during this portion of the $200 \mu$ s pulse. 
It was not possible to resolve $\mathrm{Al}^{2+}$ from the $\mathrm{N}^{+}$signal during reactive Al-HIPIMS due to peak overlap ( $m / e=13.5$ and 14 , respectively). Therefore, upper bounds for the relative ratios between doubly-ionized and singly-ionized $\mathrm{Al}$ ion fluxes, $J_{A l^{2+}} J_{A l^{+}}$and doubly-ionized $\mathrm{Al}^{2+}$ and

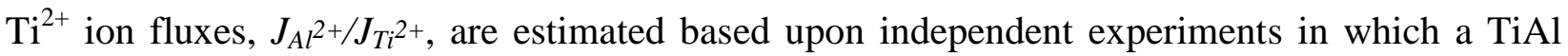
target $(70$ at\% $\mathrm{Al})$ is sputtered in pure $\mathrm{Ar}$ at $0.4 \mathrm{~Pa}(3 \mathrm{mTorr})$ in HIPIMS mode $(2.5 \mathrm{~kW}, 500 \mathrm{~Hz})$. The results show that $J_{A l^{2+}}$ is negligible.

Ion saturation current densities $J_{s}$ are measured using a 15-mm-diameter circular probe mounted at the substrate position. To minimize edge effects, the probe and surrounding holder are maintained at the same potential with the surface of the probe in the plane of the holder and separated by an $\sim 0.5$-mm-wide gap. Measurements are performed in time-averaged mode at ambient temperature; gas composition and total pressure are the same as during film growth. $J_{s}$ is obtained as a function of de magnetron power for Al-HIPIMS/Ti-DCMS and Ti-HIPIMS/AlDCMS configurations, as well as for separate $\mathrm{Al}$ and Ti targets operated one at a time in DCMS and HIPIMS modes.

As-deposited alloy film compositions are determined by time-of-flight energy elastic recoil detection analyses (ToF-E ERDA) ${ }^{23}$ carried out at the tandem accelerator in Uppsala University. A $40 \mathrm{MeV}{ }^{127} \mathrm{I}^{9+}$ probe beam is incident at $67.5^{\circ}$ with respect to the sample surface normal; recoils are detected at $45^{\circ}$. Film thicknesses are measured by cross-sectional scanning electron microscopy (SEM) in a LEO 1550 instrument. Topographical maps are obtained by tappingmode atomic force microscopy (AFM) performed using Veeco Dimension 3100 instrument with a Nanoscope IIIa controller. 
$\theta-2 \theta$ x-ray diffraction (XRD) scans, and $\sin ^{2} \psi$ analyses ${ }^{24}$ for residual stress determinations, are obtained using a Philips X'Pert MRD system operated with point-focused $\mathrm{Cu}$ $\mathrm{K} \alpha$ radiation. With the $\sin ^{2} \psi$ technique ${ }^{24}$ film strain $\varepsilon$ is evaluated by measuring the position of a Bragg reflection to obtain the corresponding film interplanar spacing $d$ as a function of the tilt angle $\psi$ between the sample normal and the scattering plane defined by incoming and diffracted x-ray beams. The film strain $\varepsilon$ as a function of the tilt angle $\psi$, defined with respect to the substrate normal, is equal to the normalized difference between $d$ and the relaxed interplanar spacing $d_{o}$,

$$
\varepsilon(\psi)=\frac{d-d_{o}}{d_{o}} .
$$

Measured $\varepsilon(\psi)$ values are used to determine the residual stress $\sigma$ through Hooke's law of linear elasticity as: $:^{24}$

$$
\varepsilon(\psi)=\frac{1+v}{E} \sigma \sin ^{2} \psi-\frac{2 v}{E} \sigma,
$$

where $v$ is Poisson's ratio and $E$ is the elastic modulus. Experimentally, the in-plane stress is extracted from the slope of $\varepsilon(\psi) v s \cdot \sin ^{2} \psi$.

Relaxed $\mathrm{Ti}_{1-x} \mathrm{Al}_{x} \mathrm{~N}$ lattice constants $a_{o}$ are determined as a function of $x$ from $\theta-2 \theta$ scans acquired at the strain-free tilt angle $\psi^{*}$, defined by setting $\varepsilon=0$ in Eq. (2):

$$
\psi^{*}=\arcsin \left(\sqrt{\frac{2 v}{1+v}}\right) .
$$

While $v(x)$ is unknown for $\operatorname{Ti}_{1-x} \mathrm{Al}_{x} \mathrm{~N}, v$ for common transition-metal nitrides varies only from 0.17 for cubic $\mathrm{AlN}^{25}$ to 0.25 for $\mathrm{TiN}^{26}$. Variation in $v$ over this range changes $\psi^{*}$ by less than \pm 
$3^{\circ}$. Here, we use $v=0.19$ as calculated for cubic $\mathrm{Ti}_{1-x} \mathrm{Al}_{x} \mathrm{~N}(0.5 \leq x \leq 0.75)^{27}$ what yields $\psi^{*}=$ $34.4^{\circ}$.

Preferred film orientations are obtained from integrated diffraction peak intensities $I_{h k l}$ which are normalized to corresponding results from powder diffraction patterns. For example, the degree of 111 texture in a film exhibiting both 111 and 002 diffraction peaks is expressed as $I_{111} /\left(I_{111}+I_{002}\right)$.

A Berkovich nanoindenter is used to determine nanoindentation hardness $H$ and elastic modulus $E$ (ref. 28) vs. film composition for as-deposited and annealed $\operatorname{Ti}_{1-x} \mathrm{Al}_{x} \mathrm{~N}$ alloys. A minimum of 20 indents, with a maximum load of $25 \mathrm{mN}$, are made in each sample. The indentation depth varies from 800 to $2000 \AA$ and does not exceed $10 \%$ of the film thickness in order to minimize substrate effects in the measurements.

Cross-sectional transmission electron microscopy (XTEM) specimens are prepared by mechanical polishing, followed by $\mathrm{Ar}^{+}$ion milling (3-4 h) carried out at $5 \mathrm{kV}$ with an $8^{\circ}$ incidence angle. During the final thinning stages (10-20 min), the ion energy and incidence angle are reduced to $2.5 \mathrm{kV}$ and $5^{\circ}$, respectively. Film microstructure is analyzed using an FEI Tecnai G2 TF 20 UT microscope operated at $200 \mathrm{kV}$. Energy dispersive spectroscopy (EDS) mapping, to assess lateral compositional uniformity, is performed in the scanning transmission electron microscopy (STEM) mode.

\section{Results}

\section{A) Ion irradiation during film growth}

Ion-energy-distribution functions at the substrate are plotted in Figure 1 for $\mathrm{Al}$ and $\mathrm{Ti}$ targets sputtered separately in both HIPIMS and DCMS modes. Average ion energies and 
percentage contributions to the total ion flux are listed in Table 1. From separate experiments

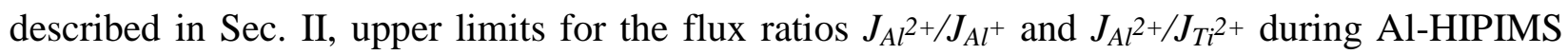
are estimated to be $<0.002$ and $<0.02$, respectively, and hence insignificant. For Al-DCMS, $J_{A l^{2+}}$ is not detected.
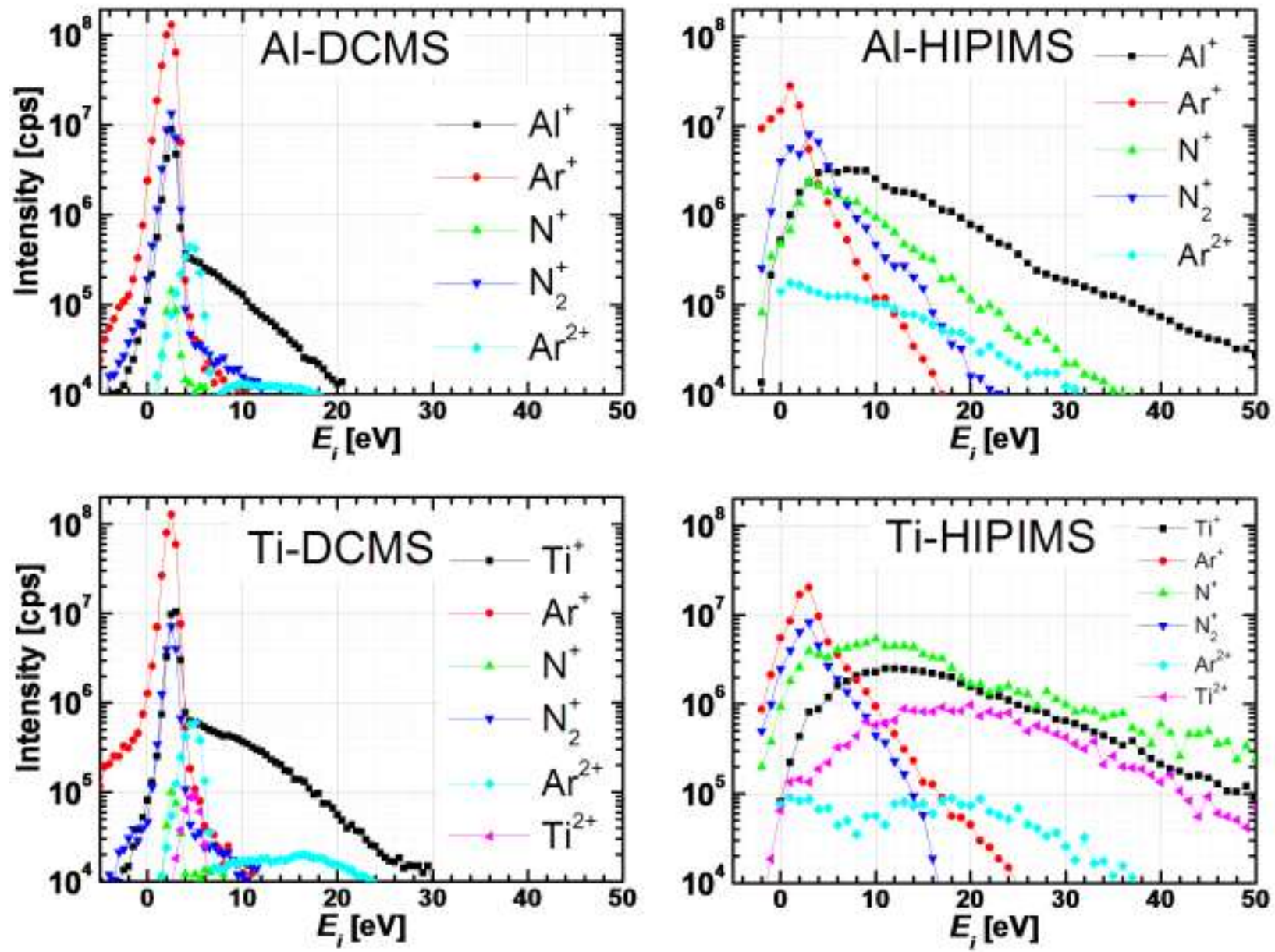

Fig. 1. Ion energy distribution functions (IEDFs) from $\mathrm{Al}$ and $\mathrm{Ti}$ targets operated in both DCMS and HIPIMS modes. The DCMS data are time-averaged. For HIPIMS, the IEDFs correspond to the highest target current density, 20- $\mu$ s, portion of the $200 \mu$ s pulses.

As is evident from Fig. 1, ion fluxes from targets operated in the DCMS mode are dominated by low-energy gas ions (primarily $\mathrm{Ar}^{+}$and $\mathrm{N}_{2}{ }^{+}$). Mean ion energies (and fraction of the total ion flux) at the substrate plane are $2.2 \mathrm{eV}(85.5 \%)$ for $\mathrm{Ar}^{+}$and $2.5 \mathrm{eV}(8.1 \%)$ for $\mathrm{N}_{2}^{+}$ from the $\mathrm{Al}$ target and $2.3 \mathrm{eV}\left(\mathrm{Ar}^{+} 84 \%\right)$ and $2.8 \mathrm{eV}\left(\mathrm{N}_{2}{ }^{+} 4.9 \%\right)$ from the Ti target with energy 
distributions at half-maximum intensities of 1.35 and $1.20 \mathrm{eV}$ for $\mathrm{Ar}^{+}$and $\mathrm{N}_{2}^{+}$, respectively. Metal ion fluxes are an order of magnitude lower with energies of $3.4 \mathrm{eV}\left(\mathrm{Al}^{+}\right)$and $4.8 \mathrm{eV}\left(\mathrm{Ti}^{+}\right)$.

Table 1. Mean ion energy and percentage contribution to the total ion flux (in parentheses) for all four ion sources. $(*)$ indicates value obtained in a separate experiments (see text).

\begin{tabular}{|c|c|c|c|c|c|c|c|c|}
\hline Ion & $\mathrm{Al}^{+}$ & $\mathrm{Al}^{2+}$ & $\mathrm{Ti}^{+}$ & $\mathrm{Ti}^{2+}$ & $\mathrm{Ar}^{+}$ & $\mathrm{Ar}^{2+}$ & $\mathrm{N}_{2}^{+}$ & $\mathrm{N}^{+}$ \\
\hline Al-HIPIMS & $\begin{array}{c}11.4 \\
(27.4 \%)\end{array}$ & $(0.05 \%)^{+}$ & - & - & $\begin{array}{c}1.8 \\
(37.3 \%)\end{array}$ & $\begin{array}{c}10.5 \\
(1.4 \%)\end{array}$ & $\begin{array}{c}3.7 \\
(22.2 \%)\end{array}$ & $\begin{array}{c}7.7 \\
(11.7 \%)\end{array}$ \\
\hline Al-DCMS & $\begin{array}{c}3.4 \\
(5.8 \%)\end{array}$ & - & - & - & $\begin{array}{c}2.2 \\
(85.5 \%)\end{array}$ & $\begin{array}{c}6.2 \\
(0.5 \%)\end{array}$ & $\begin{array}{c}2.5 \\
(8.1 \%)\end{array}$ & $\begin{array}{c}5.5 \\
(0.1 \%)\end{array}$ \\
\hline Ti-HIPIMS & - & - & $\begin{array}{c}17.7 \\
(17.9 \%)\end{array}$ & $\begin{array}{c}20.8 \\
(7.5 \%)\end{array}$ & $\begin{array}{c}3.6 \\
(26.8 \%)\end{array}$ & $\begin{array}{c}15.9 \\
(0.8 \%)\end{array}$ & $\begin{array}{c}3.7 \\
(12.2 \%)\end{array}$ & $\begin{array}{c}15.2 \\
(34.8 \%)\end{array}$ \\
\hline Ti-DCMS & - & - & $\begin{array}{c}4.8 \\
(10 \%)\end{array}$ & $\begin{array}{c}8.9 \\
(0.2 \%)\end{array}$ & $\begin{array}{c}2.3 \\
(84 \%)\end{array}$ & $\begin{array}{c}7.2 \\
(0.8 \%)\end{array}$ & $\begin{array}{c}2.8 \\
(4.9 \%)\end{array}$ & $\begin{array}{c}11.8 \\
(0.1 \%)\end{array}$ \\
\hline
\end{tabular}

In contrast, energetic high-intensity fluxes of metal ions are obtained during HIPIMS

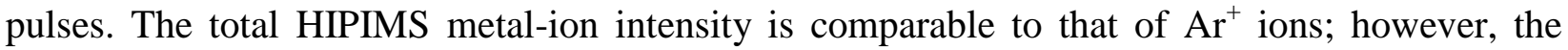
mean metal-ion energy is significantly higher (11.4 and $17.7 \mathrm{eV}$ for $\mathrm{Al}^{+}$and $\mathrm{Ti}^{+}$vs. 1.8 and 3.6 $\mathrm{eV}$ for $\mathrm{Ar}^{+}$). In addition, a high flux of doubly-ionized $\mathrm{Ti}^{2+}$ ions, with a mean ion energy of 20.8 $\mathrm{eV}$, is also obtained from the Ti target operated in HIPIMS mode, while the flux of $\mathrm{Al}^{2+}$ ions from the HIPIMS Al target is negligible. $\mathrm{N}^{+}$ions (mean $E_{i}=7.7 \mathrm{eV}$ for Al-HIPIMS and $15.2 \mathrm{eV}$ for Ti-HIPIMS) are incident at the substrate with a flux that is particularly intense for TiHIPIMS. Ion-energy-distribution functions obtained during Ti-HIPIMS exhibit high-energy tails extending to 38,44 , and $40 \mathrm{eV}$ for $\mathrm{Ti}^{+}, \mathrm{Ti}^{2+}$ and $\mathrm{N}^{+}$ions, respectively, at intensities corresponding to $90 \%$ of values measured at the mean ion energies. $\mathrm{Al}^{+}$and $\mathrm{N}^{+}$IEDFs from the Al-HIPIMS target have energy tails that extend to 25 and $17 \mathrm{eV}$, respectively.

Ion saturation current densities $J_{s}$ increase linearly with power for all target configurations, single and hybrid. During hybrid operation, total $J_{s}$ values are approximately equal to the sum of 
the constituent HIPIMS and DCMS ion current densities. For Ti and Al targets operated in DCMS mode, $J_{s}$ increases from $0.1 \mathrm{~mA} / \mathrm{cm}^{2}$ with $P_{d c}=0.7 \mathrm{~kW}$ to $0.6(\mathrm{Ti})$ and $0.8 \mathrm{~mA} / \mathrm{cm}^{2}(\mathrm{Al})$ with $P_{d c}=4 \mathrm{~kW} .5 \mathrm{~kW}$ Ti-HIPIMS and $2.5 \mathrm{~kW}$ Al-HIPIMS operation yield values of 0.8 and 0.6 $\mathrm{mA} / \mathrm{cm}^{2}$, respectively. For Al-HIPIMS/Ti-DCMS, with the average power to the HIPIMS target set to $2.5 \mathrm{~kW}$ (as during film growth), $J_{s}$ increases from $0.7 \mathrm{~mA} / \mathrm{cm}^{2}$ with dc magnetron power $P_{d c}=1.4 \mathrm{~kW}$ to $0.9 \mathrm{~mA} / \mathrm{cm}^{2}$ with $P_{d c}=4 \mathrm{~kW}$. In the Ti-HIPIMS/Al-DCMS configuration operated with an average Ti target power of $5 \mathrm{~kW}, J_{s}=0.8 \mathrm{~mA} / \mathrm{cm}^{2}$ with $P_{d c}=0.7 \mathrm{~kW}$ at the Al magnetron and increases linearly to $1.4 \mathrm{~mA} / \mathrm{cm}^{2}$ with $P_{d c}=4 \mathrm{~kW}$. The ion-to-metal flux ratio $J_{i} / J_{M e}=2-3$ during Al-HIPIMS/Ti-DCMS deposition and 3-6 during Ti-HIPIMS/Al-DCMS operation. Note that for HIPIMS, $J_{M e}$ is the total deposited metal flux, including both ions and neutrals.

\section{B) Film composition}

$\mathrm{Ti}_{1-x} \mathrm{Al}_{x} \mathrm{~N}$ film growth in hybrid HIPIMS/DCMS operation proceeds via the superposition of a constant metal flux from the DCMS target and a pulsed metal flux from the HIPIMS target. Solid-solution alloy films are found, based upon XRD, XTEM, and EDS analyses, to be compositionally uniform. The in-depth compositional uniformity derives from the relatively high frequency $(500 \mathrm{~Hz})$ and low duty cycle $(10 \%)$ of the HIPIMS pulses giving rise to AlN and TiN coverages deposited per pulse of $2.0 \times 10^{-3}$ and $0.7 \times 10^{-3} \mathrm{ML}$, respectively. This, in turn, limits the coverages deposited between HIPIMS pulses from the DCMS-driven targets to $<3.0 \times 10^{-3} \mathrm{ML}$ for $\mathrm{TiN}$ and $<2.0 \times 10^{-3} \mathrm{ML}$ for AlN in order to maintain film compositions within the desired concentration range. Near-surface ion mixing during deposition also assists in insuring compositional uniformity. 
ERDA elemental analyses reveal that $\operatorname{Ti}_{1-x} \mathrm{Al}_{x} \mathrm{~N}$ films grown using the Al-HIPIMS/TiDCMS configuration are stoichiometric, $\mathrm{N} /(\mathrm{Al}+\mathrm{Ti})=1$, to within measurement accuracy $( \pm$ 0.01), with AlN compositions $0.40 \leq x \leq 0.76$. Trapped Ar concentrations are below the detection limit $(<0.1$ at $\%)$ for films with $0.40 \leq x \leq 0.64$. At higher AlN concentrations, the Ar content increases from 0.2 at $\%$ at $x=0.68$ to 0.5 at $\%$ with $x=0.72-0.76$. Alloy films grown in the Ti-HIPIMS/Al-DCMS configuration are slightly overstoichiometric, $\mathrm{N} /(\mathrm{Al}+\mathrm{Ti})=$ $1.045 \pm 0.005$, for AlN compositions $0.41 \leq x \leq 0.74$. Ar is detected ( 0.2 at $\%)$ only in films with $x=0.74$. Oxygen concentrations in all films range from 0.3 to 1 at $\%$.

Fig. 2 shows AlN concentrations $x$ as a function of magnetron dc power $P_{d c}$ for $\mathrm{Ti}_{1-x} \mathrm{Al}_{x} \mathrm{~N}$ alloy films grown in both Al-HIPIMS/Ti-DCMS and Ti-HIPIMS/Al-DCMS configurations. Since the average HIPIMS power is maintained constant, $x$ decreases with $P_{d c}$ in the former case and increases in the latter. Al-HIPIMS/Ti-DCMS film concentrations decrease linearly from $x=$ 0.76 with $P_{d c}=1.40 \mathrm{~kW}$, to $0.72,0.68,0.64,0.59,0.56$, and 0.47 with $P_{d c}=1.40,1.60,1.80$, $2.00,2.25,2.50$ and $3 \mathrm{~kW}$, respectively. Thereafter, $x$ decreases less rapidly to 0.43 with 3.50 $\mathrm{kW}$, and finally to 0.40 with $P_{d c}=4 \mathrm{~kW}$. In the case of $\mathrm{Ti}_{1-x} \mathrm{Al}_{x} \mathrm{~N}$ films grown in the TiHIPIMS/Al-DCMS configuration, AlN concentrations increase rapidly from 0.41 with $P_{d c}=0.75$ $\mathrm{kW}$, to 0.53 with $1 \mathrm{~kW}, 0.59$ with $1.25 \mathrm{~kW}$, and 0.66 with $1.50 \mathrm{~kW}$. $x$ increases more slowly at higher dc powers to $0.74(2 \mathrm{~kW})$. 


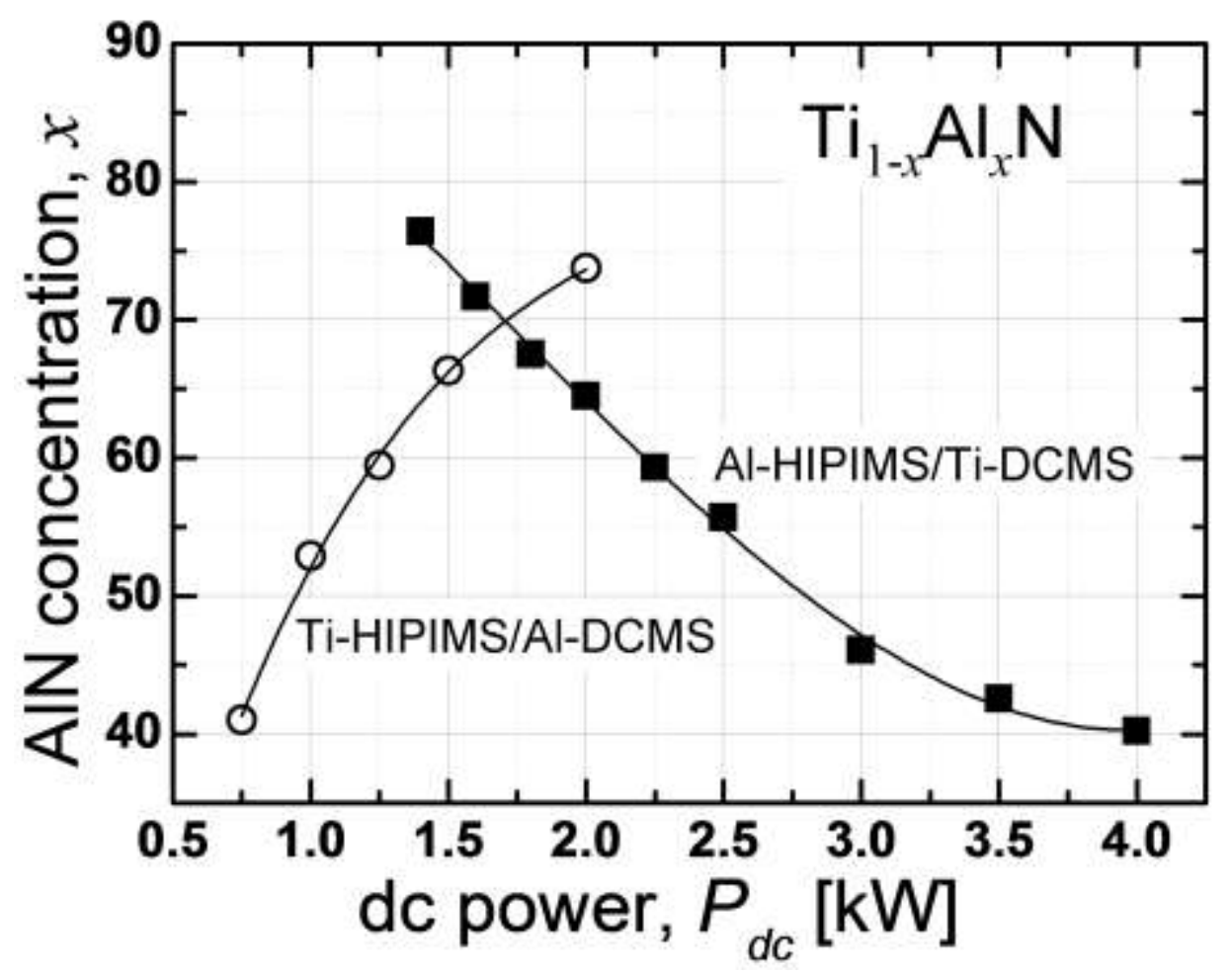

Fig. 2. AlN concentrations in $\mathrm{Ti}_{1-x} \mathrm{Al}_{x} \mathrm{~N}$ films, grown using Al-HIPIMS/Ti-DCMS (filled squares) and Ti-HIPIMS/Al-DCMS (open circles), as a function of DCMS power.

\section{C) Film microstructure}

All films are analyzed by XRD. For each sample, a series of $\theta-2 \theta$ scans is obtained at tilt angles $\psi$ varied from $0^{\circ}$ to $75^{\circ}$ in steps of $5^{\circ}$. Representative sets of comparative XRD data for $\mathrm{Ti}_{1-x} \mathrm{Al}_{x} \mathrm{~N}$ alloy films are shown in Figure 3: (a) $x=0.40$, Al-HIPIMS/Ti-DCMS, (b) $x=0.41$, TiHIPIMS/Al-DCMS, (c) $x=0.59$, Al-HIPIMS/Ti-DCMS, and (d) $x=0.59$, Ti-HIPIMS/Al-DCMS. The diffraction peaks from Al-HIPIMS/Ti-DCMS films with $x=0.40$ (Fig. 3a), are clearly shifted toward higher diffraction angles with respect to reference TiN powder patterns ${ }^{29}$ (e.g., $2 \theta_{002}=43.23^{\circ}$ vs. $42.60^{\circ}$ for TiN); whereas the Ti-HIPIMS/Al-DCMS (Fig. 3b) peak positions are closer to those for $\operatorname{TiN}\left(2 \theta_{002}=42.90^{\circ}\right.$ vs. $42.60^{\circ}$ for $\left.\mathrm{TiN}\right)$. The measured $2 \theta$ values are obtained at $\psi=35^{\circ}$, close to the strain-free tilt angle $\psi^{*}$ (ref. 24 and discussion below). At the 
higher AlN concentration, $x=0.59$, films grown in the Al-HIPIMS/Ti-DCMS configuration (Fig. 3c) are single phase, with the $\mathrm{NaCl}$ structure, and diffraction peaks exhibit even larger shifts toward higher $2 \theta$ angles $\left(2 \theta_{002}=43.36^{\circ}\right)$. In contrast, Ti-HIPIMS/Al-DCMS films (Fig. 3d) consist of a mixture of cubic and wurtzite AlN phases, with the wurtzite peaks at lower diffraction angles. Approximate volume fractions, estimated from integrated 002 and $10 \overline{1} 0$ peak intensities normalized to random powder diffraction values, are $47 \%$ cubic and $53 \%$ wurtzite.

For Ti-HIPIMS/Al-DCMS films, the $10 \overline{1} 0$ peak from the AlN-rich wurtzite phase, first detected by $\mathrm{XRD}$ in the $\mathrm{Ti}_{0.41} \mathrm{Al}_{0.59} \mathrm{~N}$ sample, increases in intensity with increasing $x$; at $x \geq 0.74$, the cubic phase is no longer detected. However, the cubic phase persists to higher AlN concentrations in Al-HIPIMS/Ti-DCMS films, for which the hexagonal phase is first detected at $x=0.67$, essentially equal to the AIN concentration at which the mixing enthalpy (and thus the chemical driving force for decomposition) is predicted to be at a maximum. ${ }^{5,30,31}$ Even for the highest AlN concentration Al-HIPIMS/Ti-DCMS film, $x=0.76$, the cubic phase $(\sim 16$ vol.\%) is still detected by XRD. In this case, however, the NaCl-structure grains are in a polycrystalline wurtzite-structure matrix.

$\mathrm{Ti}_{1-x} \mathrm{Al}_{x} \mathrm{~N}$ preferred orientation as a function of $\mathrm{AlN}$ concentration $x$ also depends strongly on target configuration as shown in Figure 4. Single-phase Al-HIPIMS/Ti-DCMS films with $x \leq$ 0.56 exhibit a strong 111 texture, which decreases and evolves to a weak 002 texture at higher $x$ values. For Ti-HIPIMS/Al-DCMS layers, the $\mathrm{NaCl}$ phase is strongly 002 at lower $\mathrm{AlN}$ concentrations, $x \leq 0.53$, and progress toward mixed 002/111 orientation with higher $x$. 
(a)
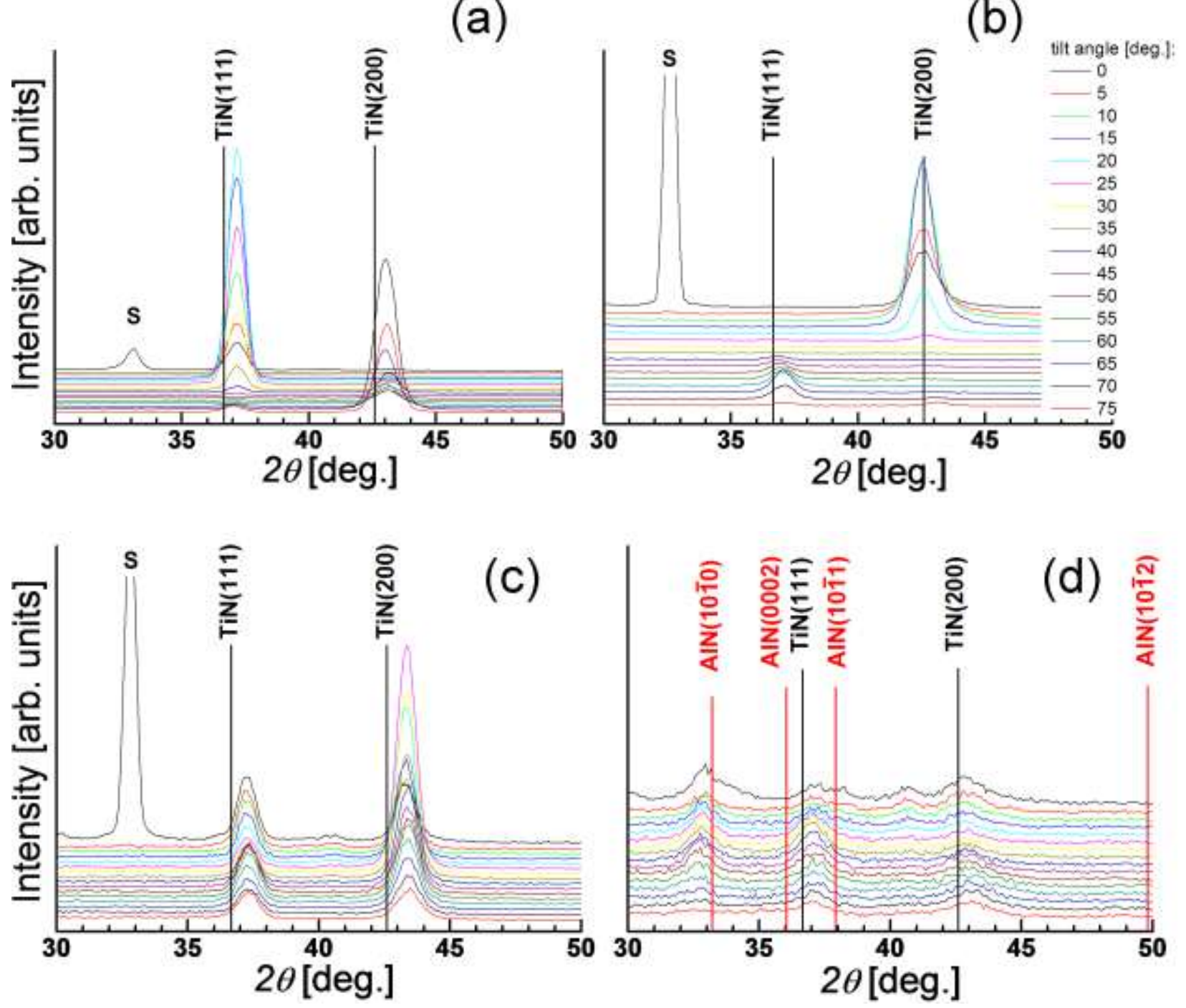

Fig. 3. $\quad \theta-2 \theta$ scans as a function of tilt angle $\psi$ for $\mathrm{Ti}_{1-x} \mathrm{Al}_{x} \mathrm{~N}$ alloy films with concentrations $x$ : (a) $x=0.40$, Al-HIPIMS/Ti-DCMS; (b) $x=0.41$, Ti-HIPIMS/Al-DCMS; (c) $x=0.59$, AlHIPIMS/Ti-DCMS; and (d) $x=0.59$, Ti-HIPIMS/Al-DCMS. 


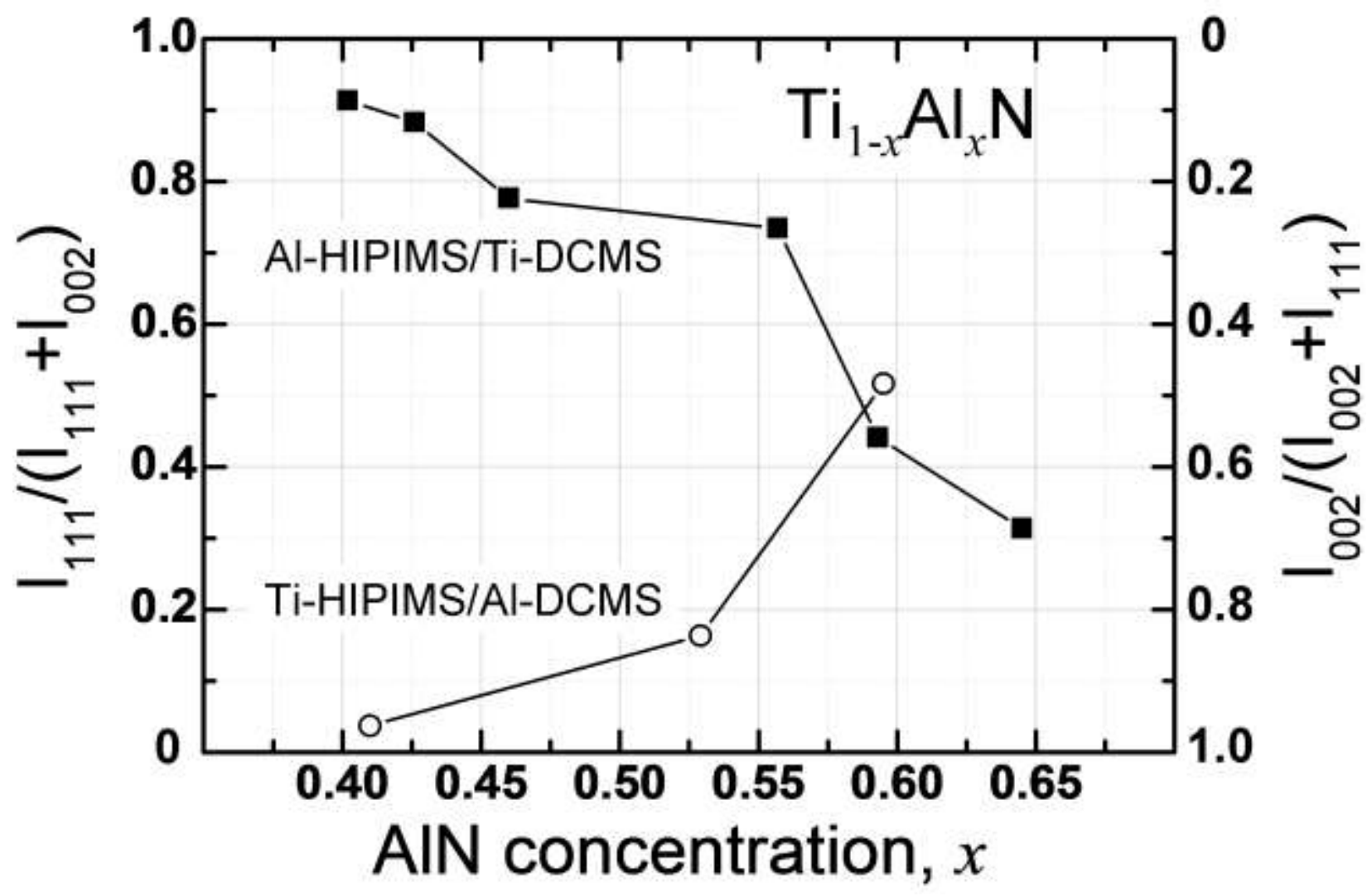

Fig. 4. Preferred orientation of $\mathrm{NaCl}$-structure $\mathrm{Ti}_{1-x} \mathrm{Al}_{x} \mathrm{~N}$ films, grown using Al-HIPIMS/TiDCMS (filled squares) and Ti-HIPIMS/Al-DCMS (open circles) target configurations as a function of AlN concentration $x$. For Ti-HIPIMS/Al-DCMS films, data points are plotted only for samples that contain sufficient volume fraction of the cubic phase to yield reliable results.

The Al-HIPIMS/Ti-DCMS integrated peak intensity ratio $I_{111} /\left(I_{111}+I_{002}\right)$, with each peak normalized to powder diffraction data, is 0.91 for $x=0.40$, decreases to 0.73 with $x=0.56$, and then decreases more rapidly to 0.44 with $x=0.59$ and 0.31 with $x=0.64$. Thus, the latter two films exhibit increasing 002 texture. $\mathrm{Ti}_{1-x} \mathrm{Al}_{x} \mathrm{~N}$ films with higher $x$ values contain wurtzitestructure second-phase AlN precipitates. Conversely, Ti-HIPIMS/Al-DCMS $\operatorname{Ti}_{1-x} \mathrm{Al}_{x} \mathrm{~N}$ films with $x=0.41$ exhibit almost complete 002 preferred orientation, $I_{002} /\left(I_{111}+I_{002}\right)=0.96$, which decreases to 0.84 with $x=0.53$ and eventually becomes mixed $002 / 111, I_{002} /\left(I_{111}+I_{002}\right)=0.48$, with $x=0.59$. $\psi$-dependent XRD results from the Ti-HIPIMS/Al-DCMS $\mathrm{Ti}_{0.47} \mathrm{Al}_{0.53} \mathrm{~N}$ layer reveal a thickness-dependent texture evolving from an initial 002 preferred orientation in the 
lower half of the film toward mixed 002/111 orientation in the upper region. Thus, the overall $I_{002} /\left(I_{111}+I_{002}\right)$ texture parameter for $\mathrm{Ti}_{0.47} \mathrm{Al}_{0.53} \mathrm{~N}$ represents a volume average.

Relaxed $\mathrm{NaCl}$-structure $\mathrm{Ti}_{1-x} \mathrm{Al}_{x} \mathrm{~N}$ alloy lattice parameters $a_{o}(x)$ are plotted in Figure 5 for all samples that contain sufficient volume fraction of the cubic phase to yield reliable results. The two target configurations yield distinctly different $a_{o}(x)$ behavior for films with similar compositions. $a_{o}(x)$ for Ti-HIPIMS/Al-DCMS $\operatorname{Ti}_{1-x} \mathrm{Al}_{x} \mathrm{~N}$ films is independent of AIN concentration, with a value of $4.213 \pm 0.003 \AA$ corresponding, based upon previous results for single-phase $\mathrm{Ti}_{1-x} \mathrm{Al}_{x} \mathrm{~N}$ layers grown reactive by cathodic arc ion plating, ${ }^{9}$ to cubic $\mathrm{Ti}_{1-x} \mathrm{Al}_{x} \mathrm{~N}$ with $x \sim 0.40$. This suggests a kinetic AlN solubility limit in the cubic TiN matrix of $x_{\max } \square 0.40$ for TiHIPIMS/Al-DCMS; higher AlN concentrations give rise to the formation of wurtzite-structure second-phase precipitates.

The Al-HIPIMS/Ti-DCMS results in Figure 5 are dramatically different. $a_{o}(x)$ values for films with compositions similar to the Ti-HIPIMS/Al-DCMS layers described above, are much lower, indicative of higher AlN solubility in the cubic TiN lattice, consistent with $\theta-2 \theta$ vs. $\psi$ XRD results in Figure 3. For Al-HIPIMS/Ti-DCMS $\operatorname{Ti}_{1-x} \mathrm{Al}_{x} \mathrm{~N}$ films with $x=0.40-0.46$, measured $a_{o}$ values (4.181-4.178 ̊) are less than previously reported results for polycrystalline alloy samples $\left(a_{o}>4.19 \AA\right.$ with $\left.x=0.5\right)$. Electron diffraction results presented below reveal that these films contain a hexagonal-structure $\varepsilon-\mathrm{Ti}_{2} \mathrm{~N}$ second phase which forms due to the high $\mathrm{Ti}^{n+}$ flux. Thus, the $\mathrm{N}_{2}$ partial pressure is too low for this set of deposition conditions. 


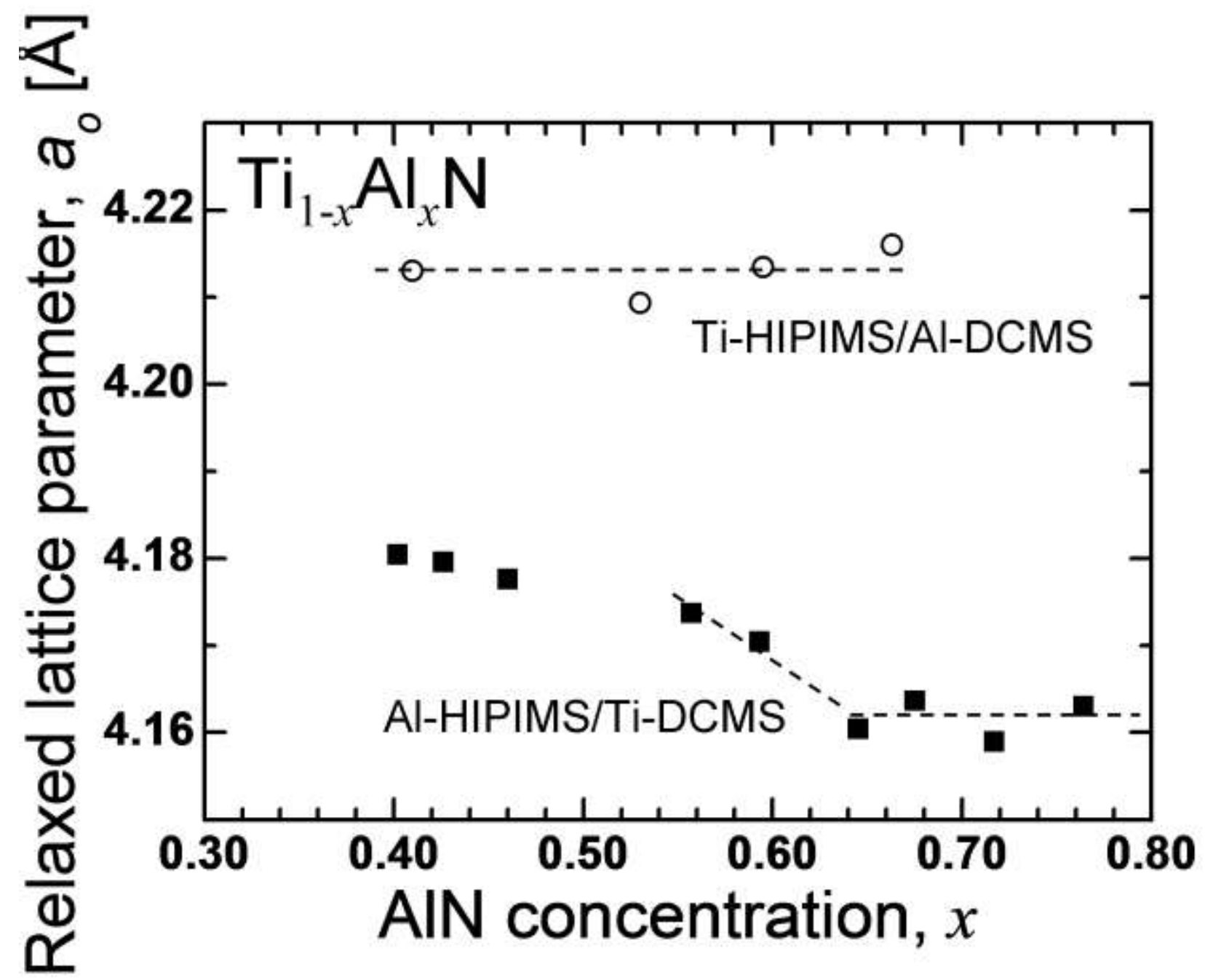

Fig. 5. Relaxed lattice parameters $a_{o}$ of $\mathrm{NaCl}$-structure $\mathrm{Ti}_{1-x} \mathrm{Al}_{x} \mathrm{~N}$ films, grown using $\mathrm{Al}$ HIPIMS/Ti-DCMS (filled squares) and Ti-HIPIMS/Al-DCMS (open circles) target configurations as a function of AlN concentration $x$.

However, for Al-HIPIMS/Ti-DCMS films with higher AlN concentrations, $x=0.56-0.64$, $a_{o}(x)$ values decrease monotonically from 4.174 to $4.160 \AA$ in good agreement with density functional theory (DFT) calculations, ${ }^{31}$ based upon projector augmented wave methods, for single-phase cubic $\mathrm{Ti}_{1-x} \mathrm{Al}_{x} \mathrm{~N}$ alloys. Moreover, the value we obtain for $x=0.64, a_{o}=4.160 \AA$, is consistent with reported results, $a_{o}=4.156 \AA$, for single-phase arc-deposited $\mathrm{Ti}_{0.34} \mathrm{Al}_{0.66} \mathrm{~N}^{8}{ }^{8} \mathrm{Al}$ HIPIMS/Ti-DCMS films with higher AlN concentrations, $x \geq 0.67$, contain second-phase 
wurtzite-structure precipitates; thus, $a_{o}(x)$ for the cubic phase remains constant over the composition range $x=0.65-0.76$.

Figures 6(a) and 6(b) are XTEM images of $\mathrm{Ti}_{0.60} \mathrm{Al}_{0.40} \mathrm{~N}$ and $\mathrm{Ti}_{0.41} \mathrm{Al}_{0.59} \mathrm{~N}$ layers grown in the Al-HIPIMS/Ti-DCMS configuration. $x=0.40$ corresponds to the film with the lowest AlN concentration and the $x=0.59$ film was chosen for its high hardness (see section III.E) and low residual stress (section III.F). Both films have a dense columnar structure with no open boundaries and an average column diameter $\langle d\rangle=300 \pm 100 \AA$. The relative intensities of the 111 , 002, and 022 diffraction rings in the corresponding selected area electron diffraction (SAED) patterns (see inserts), demonstrate that the Al-HIPIMS/Ti-DCMS $\mathrm{Ti}_{0.60} \mathrm{Al}_{0.40} \mathrm{~N}$ layer has a strong 111 texture, while $\mathrm{Ti}_{0.41} \mathrm{Al}_{0.59} \mathrm{~N}$ has a mixed 111/002 orientation; both in agreement with the XRD results (Figs. 3 and 4). No diffraction signal from wurtzite-structure AlN is detected. However, the $\mathrm{Ti}_{0.60} \mathrm{Al}_{0.40} \mathrm{~N}$ film does contain hexagonal $\varepsilon-\mathrm{Ti}_{2} \mathrm{~N}$, as revealed by the 211,111 , and 200 diffraction rings, due to the high total Ti flux during growth. The Al-HIPIMS/Ti-DCMS alloy film with $x=0.59$ is single-phase $\mathrm{NaCl}$ structure as evident from the SAED pattern in Fig. 6(b).

XTEM images of Ti-HIPIMS/Al-DCMS layers with similar compositions, $\mathrm{Ti}_{0.59} \mathrm{Al}_{0.41} \mathrm{~N}$ and $\mathrm{Ti}_{0.47} \mathrm{Al}_{0.53} \mathrm{~N}$, to those shown in Figures 6(a) and 6(b) are presented in Figures 6(c) and 6(d). The films exhibit the same dense columnar structure, with $\langle d\rangle=300 \pm 100 \AA$, as the Al-HIPIMS/TiDCMS layers. SAED patterns show that the lower-AlN-concentration film is primarily cubic, with strong 111 preferred orientation as observed by XRD. A weak $111 \varepsilon-\mathrm{Ti}_{2} \mathrm{~N}$ signal is also obtained. The higher-AIN content film, $\mathrm{Ti}_{0.47} \mathrm{Al}_{0.53} \mathrm{~N}$, is two phase and the SAED pattern exhibits both cubic $(111,002$, and 022$)$ as well as wurtzite $(0002$ and 10 $\overline{1} 0)$ diffraction rings with no preferred orientation. The latter is in contrast to the XRD results in Fig. 4 for which $I_{002} /\left(I_{111}+\right.$ $\left.I_{002}\right)=0.84$, indicating 002 preferred orientation. However, as noted above, the texture of this 
sample is thickness-dependent, ranging from 002 near the bottom to mixed 111/002 orientation near the top and the SAED pattern in Fig. 6(d) is obtained from an $~ 5000 \AA$ diameter area in the upper half of the film. High resolution XTEM images (not shown) confirm the presence of elongated $\left(\sim 200 \times 30 \AA^{2}\right)$ second-phase wurtzite-structure grains along the film growth direction.

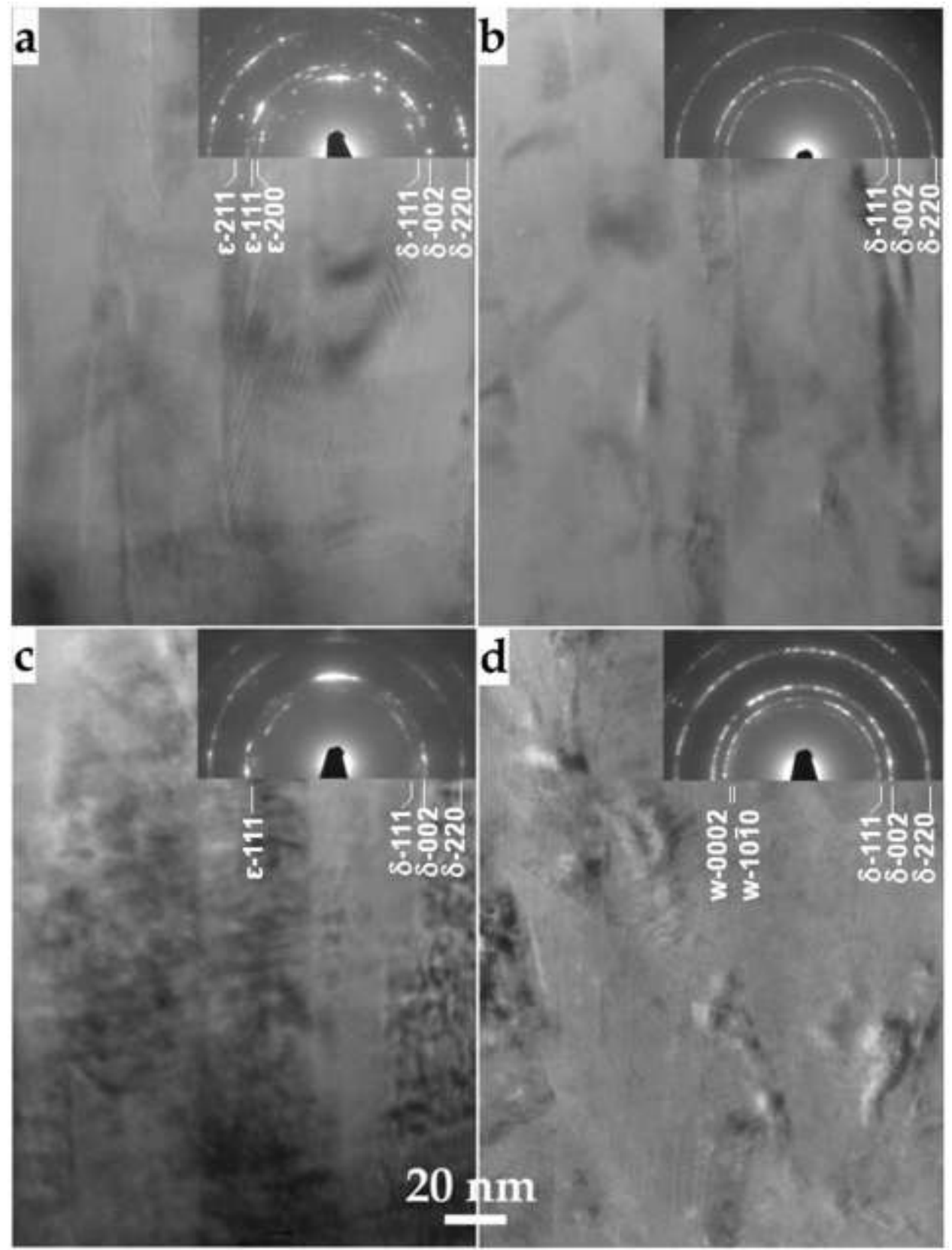

Fig. 6. XTEM images along with corresponding SAED patterns from: (a) $\operatorname{Ti}_{0.60} \mathrm{Al}_{0.40} \mathrm{~N}$ and (b) $\mathrm{Ti}_{0.41} \mathrm{Al}_{0.59} \mathrm{~N}$ grown by Al-HIPIMS/Ti-DCMS; (c) $\mathrm{Ti}_{0.59} \mathrm{Al}_{0.41} \mathrm{~N}$ and (d) $\mathrm{Ti}_{0.47} \mathrm{Al}_{0.53} \mathrm{~N}$ grown by TiHIPIMS/Al-DCMS. 


\section{D) Surface roughness}

The root-mean square (RMS) surface roughness $w(x)$, plotted in Fig. 7, is obtained for all samples from $5 \times 5 \mu \mathrm{m}$ tapping-mode AFM topographical maps. Al-HIPIMS/Ti-DCMS $\mathrm{Ti}_{1-x} \mathrm{Al}_{x} \mathrm{~N}$ films with $x=0.40$ exhibit rather high roughness, $w=91 \AA$, which decreases with increasing $x$ to reach a minimum of $34 \AA$ for $x=0.56$. At higher AlN concentrations, $w$ increases again from 72 $\AA$ with $x=0.59$ to a maximum value of $183 \AA$ at $x=0.72 . w(x)$ trends are quite different for TiHIPIMS/Al-DCMS layers. The minimum roughness, $w=23 \AA$, is obtained for films with $x=$ 0.41. $w(x)$ then increases rapidly with AlN concentration to $w=103 \AA$ with $x=0.53$ and a maximum value of $117 \AA$ at $x=0.59$. Thereafter, $w(x)$ decreases slowly to 97 and $95 \AA$ with $x=$ 0.66 and 0.74 , respectively.

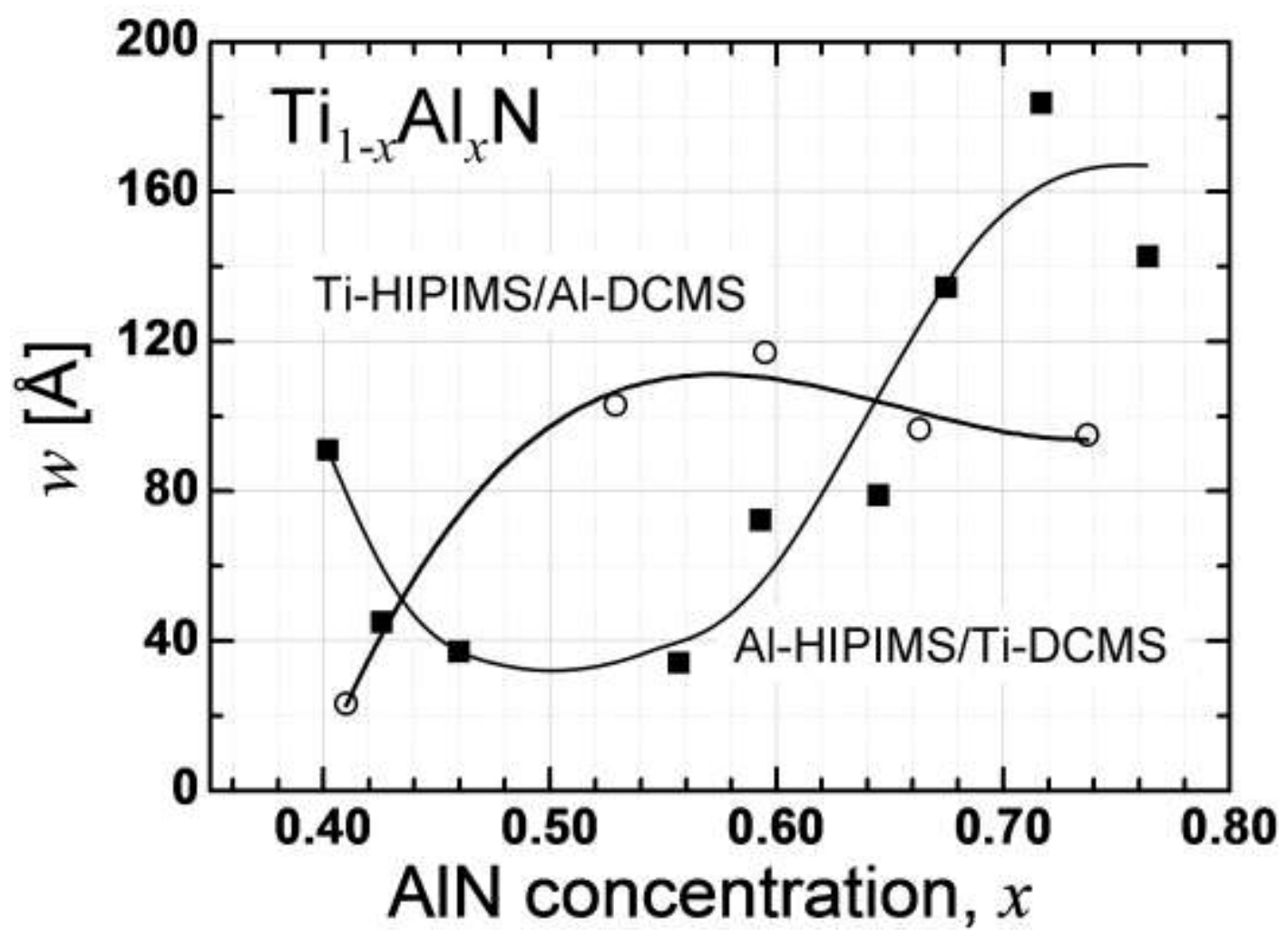

Fig. 7. RMS surface roughness $w$ of $\mathrm{Ti}_{1-x} \mathrm{Al}_{x} \mathrm{~N}$ films, grown using Al-HIPIMS/Ti-DCMS (filled squares) and Ti-HIPIMS/Al-DCMS (open circles) target configurations as a function of AlN concentration $x$. 


\section{E) Nanoindentation hardness and elastic moduli}

The nanoindentation hardness $H$ of all $\mathrm{Ti}_{1-x} \mathrm{Al}_{x} \mathrm{~N}$ films is plotted as a function of $\mathrm{AlN}$ concentration $x$ in Figure 8. Hardness values of $x \sim 0.4$ films grown with both Al-HIPIMS/TiDCMC and Ti-HIPIMS/Al-DCMS configurations are approximately the same, $\sim 24 \mathrm{GPa} . H$ initially increases with $x$ for Al-HIPIMS/Ti-DCMS layers, reaching a maximum value of $\sim 30$ GPa with $0.55 \leq x \leq 0.60$ before decreasing to $26.7 \mathrm{GPa}$ for $x=0.64$, the film with the highest AlN solubility in the cubic phase. Conversely, $H(x)$ for Ti-HIPIMS/Al-DCMS films initially decreases for $x>0.4$ to $\sim 19 \mathrm{GPa}$ with $x=0.53$, then remains approximately constant. $H(x)$ curves for Al-HIPIMS/Ti-DCMS and Ti-HIPIMS/Al-DCMS films again cross, with $H \sim 19 \mathrm{GPa}$, at $x \sim$ 0.67, and Al-HIPIMS/Ti-DCMS values decrease below $16 \mathrm{GPa}$ for two-phase films. Annealing of the $\mathrm{Ti}_{0.41} \mathrm{Al}_{0.59} \mathrm{~N}$ layers at $900{ }^{\circ} \mathrm{C}$ for $2 \mathrm{~h}$ resulted in age hardening from $30 \mathrm{GPa}$ to $33 \mathrm{GPa}$ due to spinodal decomposition of cubic AlN and TiN. ${ }^{32}$

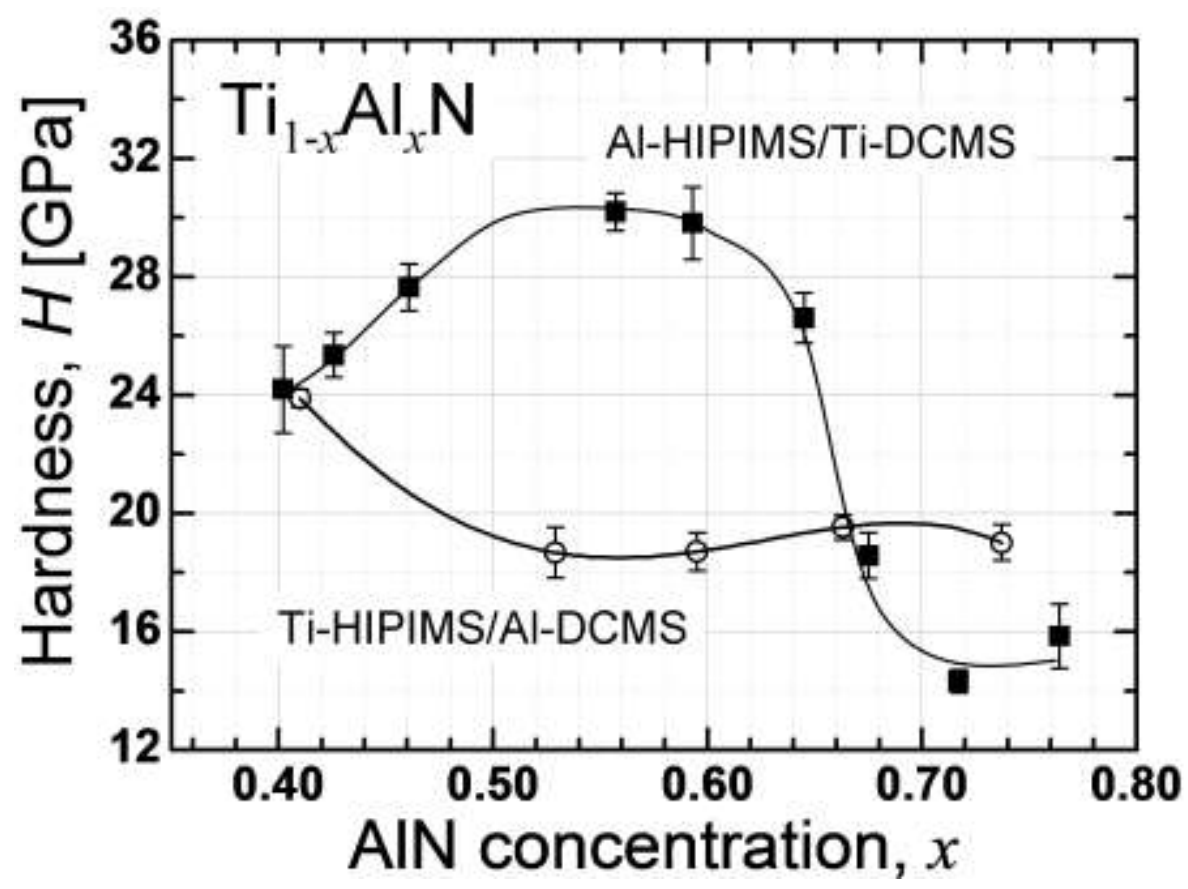

Fig. 8. Hardness $H$ of $\mathrm{Ti}_{1-x} \mathrm{Al}_{x} \mathrm{~N}$ films, grown using Al-HIPIMS/Ti-DCMS (filled squares) and TiHIPIMS/Al-DCMS (open circles) target configurations as a function of AlN concentration $x$. 
Nanoindentation elastic moduli $E$ are plotted as a function of AlN concentration $x$ in Figure 9. For Al-HIPIMS/Ti-DCMS films, $E$ varies from $369 \mathrm{GPa}$ with $x=0.40$ to $408 \mathrm{GPa}$ with $x=$ 0.59 , then decreases rapidly to $283 \mathrm{GPa}$ with $x=0.64$, and even more rapidly to $242 \mathrm{GPa}$ with $x=$ 0.67 and $\sim 197 \mathrm{GPa}$ for $x \geq 0.72$. In contrast, measured $E$ values for Ti-HIPIMS/Al-DCMS films are low over the entire range of AlN concentrations, varying from $229 \mathrm{GPa}$ with $x=0.41$ to 243 GPa with $x=0.75$.

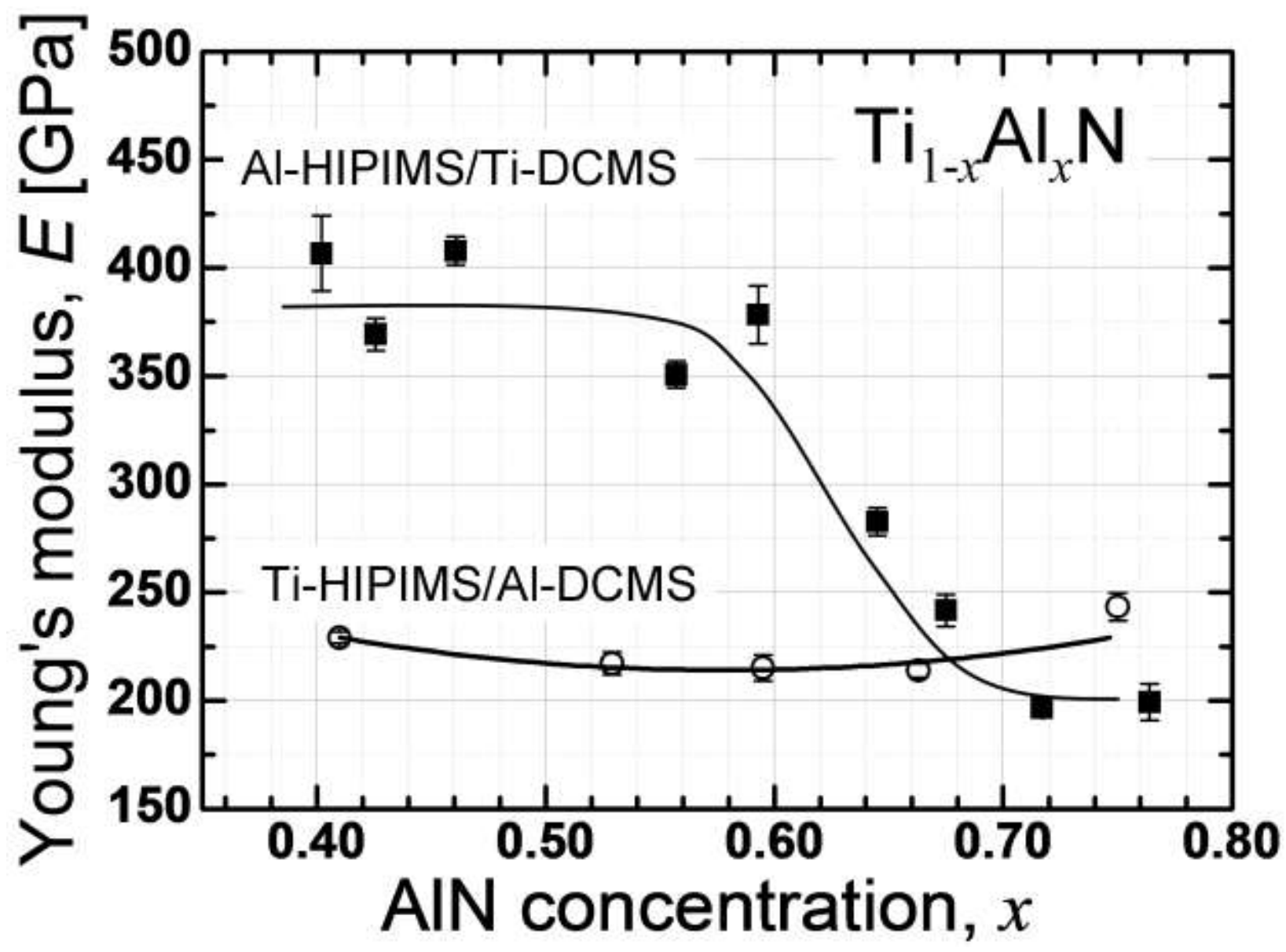

Fig. 9. Elastic moduli $E$ of $\mathrm{Ti}_{1-x} \mathrm{Al}_{x} \mathrm{~N}$ films, grown using Al-HIPIMS/Ti-DCMS (filled squares) and Ti-HIPIMS/Al-DCMS (open circles) target configurations as a function of AlN concentration $x$. 


\section{F) Residual stress}

Residual stress values $\sigma$ obtained from $\sin ^{2} \psi$ analyses, carried out for both Al-HIPIMS/TiDCMS and Ti-HIPIMS/Al-DCMS films, are determined as a function of film composition $x$. For this purpose, lattice spacings $d_{\psi}$ are obtained for each film from the position of the $422 \mathrm{TiN}$ Bragg reflection, at ten different values of the tilt angle $\psi$ ranging from $0^{\circ}$ and $72^{\circ}$, to generate a plot $\varepsilon(x)$ of $\left(d_{\psi^{-}}-d_{0}\right) / d_{0}$ vs. $\sin ^{2} \psi$. Figure 10 shows typical results for films, with similar composition $\mathrm{x} \sim 0.55$, grown using Al-HIPIMS/Ti-DCMS and Ti-HIPIMS/Al-DCMS. The difference in the slope and sign of the curves reflects the type, compressive $v s$. tensile, of residual stress in the layers. Elastic moduli $E(x)$, required for obtaining $\sigma(x)$ values using Eq. (2), are obtained from Fig. 9. $\sigma(x)$ results, plotted in Fig. 11 for all samples that contain a sufficient volume of the cubic phase to allow reliable measurements, reveal large differences in stress for Al-HIPIMS/Ti-DCMS vs. Ti-HIPIMS/Al-DCMS films with similar compositions. While TiHIPIMS/Al-DCMS films exhibit significant compressive stress ranging from 1.4 to $2.7 \mathrm{GPa}$, AlHIPIMS/Ti-DCMS films have low tensile stresses, varying from $0.2 \mathrm{GPa}$ with $x=0.64$ to 1.2 GPa with $x=0.43$.

\section{Discussion}

As demonstrated in Sec. III, the choice of target configuration used to grow $\operatorname{Ti}_{1-x} A l_{x} \mathrm{~N}$ alloy films in the hybrid HIPIMS/DCMS mode has a dramatic effect on AlN solubility in the cubic TiN matrix, which in turn affects the texture, surface roughness, hardness, elastic modulus, and residual stress of as-deposited $\mathrm{Ti}_{1-x} \mathrm{Al}_{x} \mathrm{~N}$ films with similar $x$. Over the compositional range $0.55 \leq$ $x \leq 0.60, \mathrm{Ti}_{1-x} \mathrm{Al}_{x} \mathrm{~N}$ alloy films grown under periodic $\mathrm{Al}^{+}$ion irradiation exhibit hardness which is 
$1.7 \times$ higher than obtained with corresponding layers grown under periodic energetic $\mathrm{Ti}^{n+}(n=1$, 2) ion irradiation.

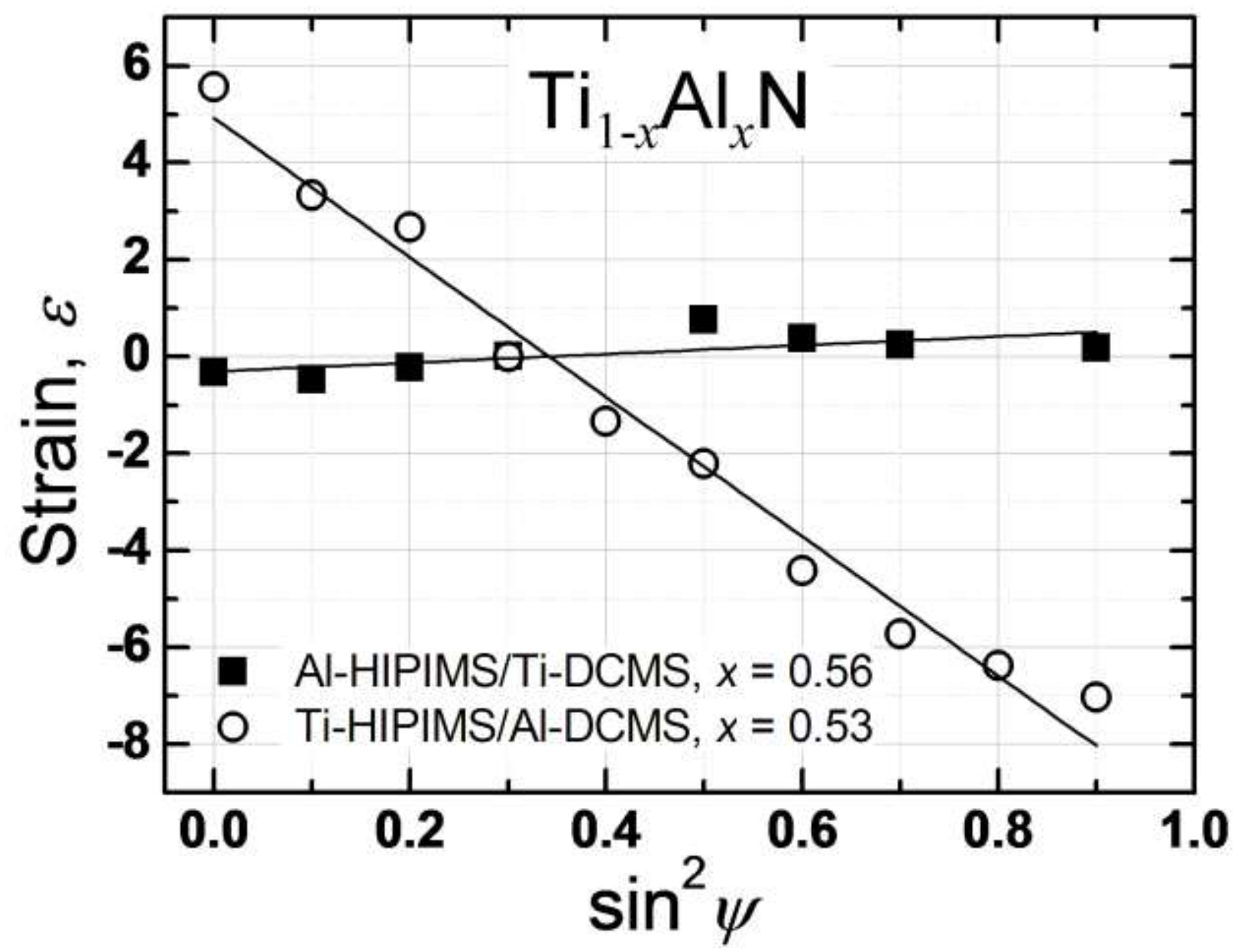

Fig. 10. Typical $\sigma v s . \sin ^{2} \psi$ plots for $\mathrm{Ti}_{1-x} \mathrm{Al}_{x} \mathrm{~N}$ films, grown using Al-HIPIMS/Ti-DCMS with $x$ $=0.56$ (filled squares) and Ti-HIPIMS/Al-DCMS with $x=0.53$ (open circles).

It has been demonstrated that ion irradiation during film growth can play a crucial and deterministic role in establishing film nanostructure. ${ }^{12}$ The kinetic energy $K E$ incident at the film surface is a product of the average ion energy $E_{i}$ and the ion-to-metal flux ratio $J_{i} / J_{M e}$. Evolution of film nanostructure follows different reaction paths when varying $E_{i}$ vs $J_{i} / J_{M e}$. High ion fluxes $\left(J_{i} / J_{M e} \geq 5\right)$ with low energy $\left(E_{i} \leq 20 \mathrm{eV}\right)$ lead to densification, larger grain size, and low stress levels in $\mathrm{Ti}_{0.5} \mathrm{Al}_{0.5} \mathrm{~N}$ films grown by magnetically unbalanced DCMS in pure $\mathrm{N}_{2}{ }^{2}$ In contrast, 
increasing $K E$ via increasing $E_{i}$, at constant $J_{i} / J_{M e}$, also leads to densification, but extracts a high price in terms of high compressive stress values due to gas ion incorporation and residual lattice defects. Precipitation of wurtzite-structure $\mathrm{AlN}$ is observed in $\mathrm{Ti}_{0.5} \mathrm{Al}_{0.5} \mathrm{~N}$ films grown with $E_{i} \geq$ $100 \mathrm{eV}$ and $J_{i} / J_{M e}=1$ (Refs. 2, 33).

In the present experiments, carried out in mixed $\mathrm{Ar} / \mathrm{N}_{2}$ atmospheres, an energetic flux of metal ions (with a high-energy tail), in addition to gas ions, is incident at the growing film during the HIPIMS pulses, as shown in Fig. 1. Sputtering from the DCMS target yields a continuous flux of low-energy ions, $E_{i} \sim 2 \mathrm{eV}$, dominated by $\mathrm{Ar}^{+}(\sim 85 \%$, see Table 1) with minor contributions from metal (6-10\%) and $\mathrm{N}_{2}^{+}(5-8 \%)$ ions. During the HIPIMS pulses, the metal ion fraction in the ionized flux bombarding the film surface increases to $\sim 27 \%$ for $\mathrm{Al}^{+}$(the $\mathrm{Al}^{2+}$ flux is insignificant) and $25 \%$ for the sum of $\mathrm{Ti}^{+}$and $\mathrm{Ti}^{2+}$ ions, which is comparable to that of $\mathrm{Ar}^{+}$ (27-37\%) ions and larger than for $\mathrm{N}_{2}^{+}(12-22 \%)$ ions. Thus, co-sputtering in a hybrid configuration in which one target is operated in HIPIMS, while the other is operated in DCMS mode, provides the opportunity to probe the effect of individual energetic metal ion fluxes, $\mathrm{Al}^{n+}$ $v s . \mathrm{Ti}^{n+}$, on the growth of metastable $\mathrm{Ti}_{1-x} \mathrm{Al}_{x} \mathrm{~N}$ films. Total metal deposition between HIPIMS pulses are $<2 \times 10^{-3} \mathrm{ML}$. Thus, freshly-deposited film atoms are exposed to incident metal ion irradiation during the subsequent HIPIMS pulse.

Our results reveal a large asymmetry between the effects of energetic $\mathrm{Al}^{n+}$ and $\mathrm{Ti}^{n+}$ ion fluxes on the evolution of film hardness (Fig. 8) and stress (Fig. 11) with increasing AlN concentration. $H(x)$ for the Al-HIPIMS/Ti-DCMS case resembles previously published results for $\mathrm{Ti}_{1-x} \mathrm{Al}_{x} \mathrm{~N}$ alloy films grown by ion-beam-assisted deposition, ${ }^{34}$ whereas $H(x)$ results for TiHIPIMS/Al-DCMS layers are more typical of films deposited by DCMS, in which alloy decomposition at relatively low AlN concentrations $(x \sim 0.5)$ leads to lower hardness. 


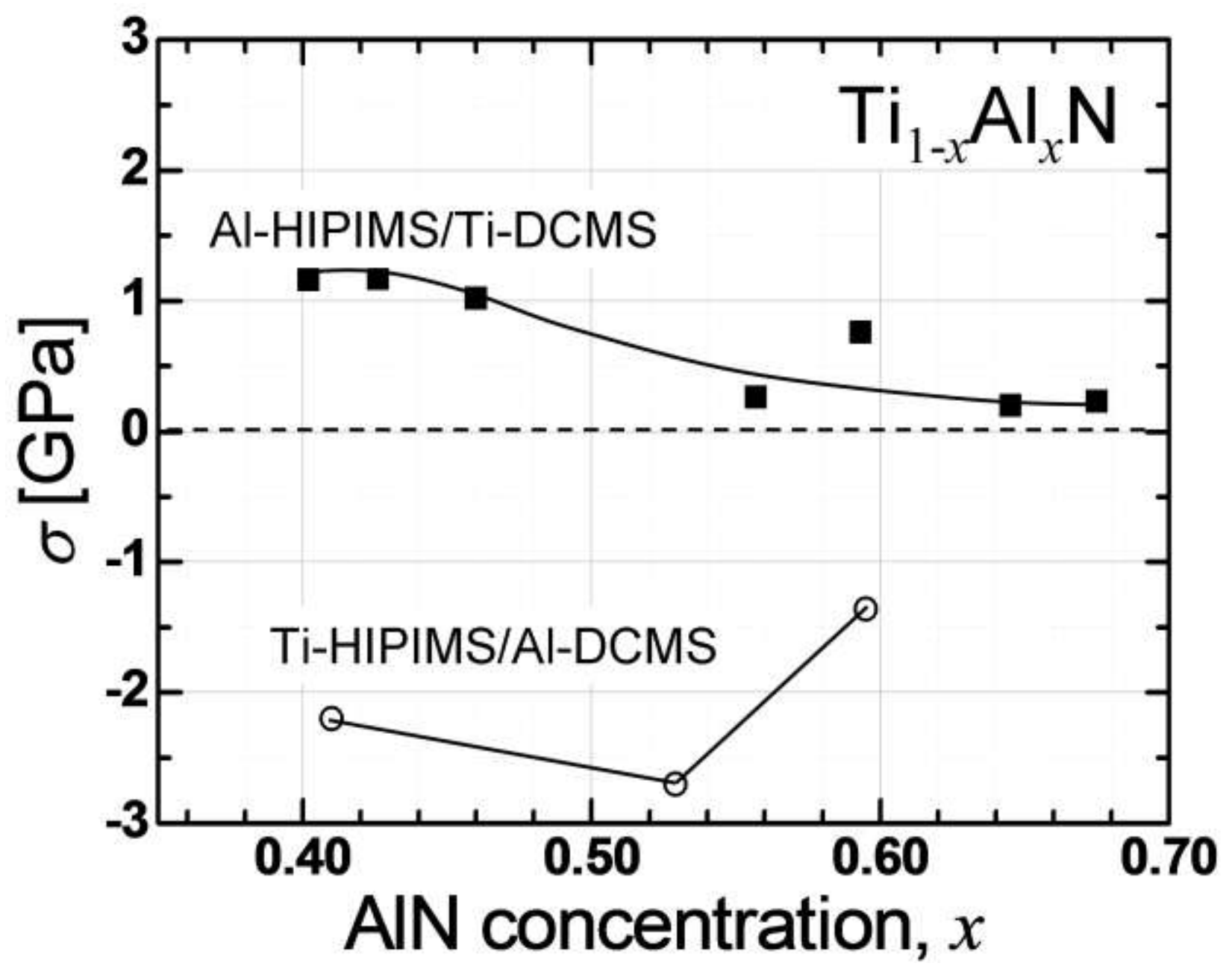

Fig. 11. Residual stress $\sigma$ of $\operatorname{Ti}_{1-x} \mathrm{Al}_{x} \mathrm{~N}$ films, grown using Al-HIPIMS/Ti-DCMS (filled squares) and Ti-HIPIMS/Al-DCMS (open circles) target configurations as a function of AlN concentration $x$.

Over the composition range $0.50 \leq x \leq 0.60, \mathrm{Ti}_{1-x} \mathrm{Al}_{x} \mathrm{~N}$ films grown in the Al-HIPIMS/TiDCMS configuration exhibit high hardness ( $\sim 30 \mathrm{GPa})$ and low tensile stress $(0.2-0.7 \mathrm{GPa})$, a unique combination of film properties for $\mathrm{Ti}_{1-x} \mathrm{Al}_{x} \mathrm{~N}$. High $H$ values are typically the result of high compressive stress which, for films prepared by cathodic arc evaporation, can range from -3.1 (ref. 8) to $-9.1 \mathrm{GPa}^{11}{ }^{11}$ In such cases, both $H$ and $\sigma$ decrease during post-annealing ${ }^{35}$ (or film applications at elevated temperatures) as residual point defects are annealed out. This does not occur with the present films. Upon post-deposition annealing at $900{ }^{\circ} \mathrm{C}, \mathrm{Ti}_{0.41} \mathrm{Al}_{0.59} \mathrm{~N}$ film 
hardness increases to $33 \mathrm{GPa}$ due to the formation of coherent cubic AlN via spinodal decomposition. $^{32}$

In distinct contrast, as-deposited Ti-HIPIMS/Al-DCMS $\mathrm{Ti}_{1-x} \mathrm{Al}_{x} \mathrm{~N}$ films with compositions $0.50 \leq x \leq 0.60$ exhibit low hardness, $\sim 18.5 \mathrm{GPa}$, and have relatively high compressive stress, 1.4-2.7 GPa. This is consistent with recently published results for $\operatorname{Ti}_{1-x} \mathrm{Al}_{x} \mathrm{~N}$ alloys co-sputtered in a similar configuration: the Ti target was powered by HIPIMS and the Al target by pulsed DC. ${ }^{36}$ The latter results show that films with an AlN concentration $x \sim 0.60$ deposited at substrate bias $V_{s}<100 \mathrm{~V}$ have low hardness $\left(10-22 \mathrm{GPa}\right.$, depending on $\left.V_{s}\right)$ and contain second-phase wurtzite AlN precipitates.

The large difference in the hardness of Al-HIPIMS/Ti-DCMS $(H \sim 30 \mathrm{GPa})$ and TiHIPIMS/Al-DCMS $(H \sim 18.5 \mathrm{GPa})$ metastable $\mathrm{Ti}_{1-x} \mathrm{Al}_{x} \mathrm{~N}$ alloys is primarily due to corresponding differences in phase content. At lower AlN concentration, $x \sim 0.4$, the two target configurations provide films with similar hardness, $H \sim 24 \mathrm{GPa}$, which are primarily $\mathrm{NaCl}$-structure, with a small volume fraction of $\varepsilon-\mathrm{Ti}_{2} \mathrm{~N}$ due to the high Ti/nitrogen flux ratio. However, significant differences in phase content between Al-HIPIMS/TI-DCMS and Ti-HIPIMS/Al-DCMS films are observed at higher $x . \mathrm{Ti}_{1-x} \mathrm{Al}_{x} \mathrm{~N}$ alloys grown in the former configuration retain the $\mathrm{NaCl}$ structure, whereas Ti-HIPIMS/Al-DCMS films contain an increasing volume fraction of hexagonal AlN, which has a low hardness and elastic modulus. ${ }^{37}$

As evident from both XRD and XTEM results in Sec. III.C, AlN solubility in NaClstructure $\mathrm{Ti}_{1-x} \mathrm{Al}_{x} \mathrm{~N}$ is significantly higher when HIPIMS is applied to the $\mathrm{Al}$, rather than the $\mathrm{Ti}$, target. With the Ti-HIPIMS/Al-DCMS configuration, the alloy is found to decompose to two phases over the composition range $\sim 0.40<x<0.53$. The NaCl-structure solubility limit extracted from the relaxed lattice constant $a_{o}(x)$ results in Fig. 5 yields $x_{\max } \square 0.40$. However, the hexagonal 
AlN phase is not detected in Al-HIPIMS/Ti-DCMS $\mathrm{Ti}_{1-x} \mathrm{Al}_{x} \mathrm{~N}$ films until $x>0.65$, which corresponds to the broad maximum in the calculated heat of mixing $\Delta H_{m i x}{ }^{5}$ Thus, Ti-HIPIMS/AlDCMS films exhibit much lower cubic AlN solubility $(x \sim 0.4)$ than both DCMS $(x \sim 0.5)^{6,7}$ and Al-HIPIMS/Ti-DCMS $(x=0.64)$. The Al-HIPIMS/Ti-DCMS result is essentially equal to maximum values reported for cathodic arc deposition $(x=0.66){ }^{8}$

The observed stark differences in phase composition and cubic AlN kinetic solubility limits between Al-HIPIMS/Ti-DCMS and Ti-HIPIMS/Al-DCMS $\mathrm{Ti}_{1-x} \mathrm{Al}_{x} \mathrm{~N}$ films with $0.50 \leq x \leq 0.60$ are due to inherently different HIPIMS ion irradiation conditions during film growth. Other deposition conditions for the two growth modes were chosen to be as alike as possible: deposition rates and total discharge powers in this alloy composition range are $3.3 \pm 0.3 \AA / \mathrm{s}$ with $4.9 \pm 0.1 \mathrm{~kW}$ for Al-HIPIMS/Ti-DCMS $2.2 \pm 0.2 \AA / s$ with $6.1 \pm 0.1 \mathrm{~kW}$ in the Ti-HIPIMS/Al-DCMS deposition mode. Moreover, in both cases, the mean energies of the primary metal and gas ions incident at the growing film surface during dc magnetron sputter deposition between the HIPIMS pulses have similar low values (due to narrow IEDFs), 12 to $13 \mathrm{eV}$ (see Table 1) including the floating potential.

However, the situation is quite different during the high-energy HIPIMS pulses. Broad metal-ion IEDFs (see Fig. 1), the presence of doubly-ionized species, and the synchronously applied substrate bias $V_{s}$ during the pulse contribute to a large increase in $E_{i}$ values. The timeaveraged ion-to-metal flux ratio $J_{i} / J_{M e}$ during film growth in the Ti-HIPIMS/Al-DCMS configuration ranges from 3 to 6 , compared to 2-3 for Al-HIPIMS/Ti-DCMS. Momentum transfer to the growing film is also more efficient due to the high fraction of metal ions in the incident flux. Of particular importance is the high flux of doubly ionized $\mathrm{Ti}^{2+}$ ions, $J_{T i^{2+}}$, with $J_{T i^{2+}} J_{T i^{+}}=0.42$. This is crucial; not only is the average energy of $\mathrm{Ti}^{2+}$ ions high $(20.8 \mathrm{eV})$, but 
the energy gain due to the applied substrate bias, $V_{s}=60 \mathrm{~V}$, is twice that for singly-ionized species. At $V_{s}=60 \mathrm{~V}$, the average energy of $\mathrm{Ti}^{2+}$ ions incident at the film is $>140 \mathrm{eV}$ during the HIPIMS pulse. This leads to the production of residual point defects ${ }^{12,33}$ which are manifested in XTEM images (Figs. 6c-d) as speckle contrast due to local strain fields associated with point defect complexes. These defects serve as nucleation centers for the formation of wurtzitestructure AlN precipitates at relatively low AlN concentrations ( $x \square 0.40)$. As a consequence of phase separation, both $H$ and $E$ are low, with values close to that of hexagonal AlN, whereas the residual stress is high (1.4-2.7 GPa).

Ion irradiation conditions during Al-HIPIMS/Ti-DCMS de magnetron operation are similar to those encountered for Ti-HIPIMS/Al-DCMS; in both cases, gas ions dominate and ion energies at the film surface are low, ranging from 12 to $15 \mathrm{eV}$. However, ion bombardment conditions during HIPIMS pulses are clearly very different. For Al-HIPIMS/Ti-DCMS film growth, the metal ion contribution to the total flux is significant $\left(\sim 27 \%\right.$ of $\left.\mathrm{Al}^{+}\right)$; however, the $\mathrm{Al}^{2+}$ flux is negligible, $J_{A l^{2}}+/ J_{T i^{2+}}<0.02$. The latter is due to three reasons. First, the mass difference between $\mathrm{Al}(m=27 \mathrm{amu})$ and $\mathrm{Ti}(m=48 \mathrm{amu})$ ions means that the transit time for sputter-ejected Al neutrals through the dense plasma region (assuming a similar ejection energy) is $\sim 30 \%$ less, thus resulting in lower probability for electron impact ionization. In addition, the second ionization potential of $\mathrm{Al}(18.83 \mathrm{eV})$ is significantly higher than that of $\mathrm{Ti}(13.57 \mathrm{eV})$, which further decreases the $2+$ ionization probability of Al vs. Ti. Finally, the higher sputter yield of $\mathrm{Al}$ (approximately twice that of $\mathrm{Ti}$ ) leads to an increased concentration of metal atoms, with a relatively low first-ionization potential, in the plasma. The consequent production of a high concentration of singly-ionized $\mathrm{Al}^{+}$cools the electron energy distribution and, hence, decreases the probability of forming doubly-ionized species. 
The lack of multiply-charged metal ions during Al-HIPIMS/Ti-DCMS deposition means that the average ion energy at the film surface during HIPIMS pulses ranges from $\sim 62\left(\mathrm{Ar}^{+}\right.$ions) to $\sim 72 \mathrm{eV}$ (metal ions) which together with the time-averaged ion-to-metal flux ratio $J_{i} / J_{M e}$ of 2-3, gives rise to effective near-surface ion mixing, thereby inhibiting the precipitation of wurtzite AlN second phase, without providing significant residual ion damage. This, in turn, enables solid solution hardening with $H(x)$ increasing from $24 \mathrm{GPa}$ with $x=0.40$ to $30 \mathrm{GPa}$ with $x=0.59$. Elastic moduli $E$ range from 350 to $410 \mathrm{GPa}$. However, with increasing $x$, the mixing enthalpy also increases and, at $x>0.65$ the driving force towards decomposition overcomes dynamic near-surface ion mixing effects, wurtzite-structure AlN precipitates out of solution, and Figs. 8 and 9 show that $H$ and $E$ decrease dramatically.

\section{Conclusions}

We use a hybrid HIPIMS/DCMS co-sputtering configuration, in which one target (either Ti or $\mathrm{Al}$ ) is powered by HIPIMS while the other is powered by DCMS, to grow metastable $\mathrm{Ti}_{1-x} \mathrm{Al}_{x} \mathrm{~N}$ alloy films with compositions $0.4 \leq x \leq 0.74$. Markedly different film growth pathways are obtained depending upon which target is powered by HIPIMS.

Alloys grown in the Al-HIPIMS/Ti-DCMS mode have a kinetic solid-solubility limit of $x=$ 0.64 and exhibit high hardness ( $H$ up to $30 \mathrm{GPa}$ ) due to solid-solution hardening with low residual tensile stress $(0.2-0.7 \mathrm{GPa})$, all of which are difficult to achieve by either DCMS alone or by cathodic arc deposition. We attribute this to a combination of kinetically-limited growth and dynamic near-surface mixing due predominantly to $\mathrm{Al}^{+}$and $\mathrm{Ar}^{+}$ion irradiation during HIPIMS pulses (the $\mathrm{Al}^{2+}$ flux is negligible). Total metal deposition between HIPIMS pulses is $<<1 \mathrm{ML}$. Ion mixing is facilitated by the enhanced momentum transfer from metal ions during HIPIMS $v s$. 
primarily gas ions during DCMS. Ion energies of $60-70 \mathrm{eV}$, with ion-to-metal flux ratios of 2-3, are low enough to avoid formation of significant residual ion damage.

In sharp contrast, with Ti-HIPIMS/Al-DCMS, two-phase $\mathrm{Ti}_{1-x} \mathrm{Al}_{x} \mathrm{~N}$ films are obtained at all compositions. The layers exhibit low hardness in the range 18-19 GPa with high compressive stress, up to $-2.7 \mathrm{GPa}$, leading to delamination upon post-annealing. The dramatic difference in film properties is primarily due to the presence of an intense flux of doubly-ionized $\mathrm{Ti}^{2+}$ ions, with a mean ion energy of $20.8 \mathrm{eV}$, during the Ti-HIPIMS pulses. $\mathrm{Ti}^{2+}$ ions, accelerated by the $-60 \mathrm{~V}$ substrate bias, with $J_{i} / J_{M e}=3-6$, have total kinetic energies $>140 \mathrm{eV}$. This is more than

enough to give rise to the creation of the residual defects ${ }^{12,33}$ we observe as speckle contrast in XTEM images and explains the high compressive stress. The defects serve as nucleation centers for the formation of wurtzite-structure AlN precipitates which decrease film hardness.

Overall, the results clearly demonstrate that the use of combined HIPIMS/DCMS cosputtering provides enhanced flexibility in tuning the microstructure and physical properties of as-deposited alloy films.

\section{Acknowledgements}

We thank Mr. Jörgen Bengtsson at IFM for help with AFM characterization. The financial support from the European Research Council (ERC) through an Advanced Grant is acknowledged. We thank the staff at CemeCon AG and at the Tandem Laboratory, Uppsala University, for technical support. 


\section{REFERENCES}

${ }^{1}$ O. Knotek, M. Böhmer, T. Leyendecker On structure and properties of sputtered Ti and Al based hard compound films J. Vac. Sci. Technol. A 4 (1986) 2695

${ }^{2}$ F. Adibi, I. Petrov, L. Hultman, U. Wahlström, T. Shimizu, D. McIntyre, J.E. Greene J. Appl. Phys. 69 (1991) 6437

${ }^{3}$ J.S. Schuster and J. Bauer, J. Solid State Chem. 53 (1984) 260

${ }^{4}$ H. Holleck, Surf. Coat. Technol. 36 (1988) 151

${ }^{5}$ B. Alling, A. V. Ruban, A. Karimi, O. E. Peil, S. I. Simak, L. Hultman and I. A. Abrikosov Mixing and decomposition thermodynamics of c-Ti1-xAlxN from first-principles calculations Physical Review B 75 (2007) 045123

${ }^{6}$ U. Wahlström, L. Hultman, J.-E. Sundgren, F. Adibi, I. Petrov and J. E. Greene Crystal growth and microstructure of polycrystalline $T i_{1-x} A l_{x} N$ alloy films deposited by ultra-high-vacuum dual-target magnetron sputtering Thin Solid Films 235 (1993) 62-70

${ }^{7}$ F. Adibi, I. Petrov, J.E. Greene, U. Wahlstrom, J.-E. Sundgren, Design and characterization of a compact twotarget ultrahigh vacuum magnetron sputter deposition system: application to the growth of epitaxial $T i_{1-x} A l_{x} N$ alloys and TiN/Ti $i_{1-x} A l_{x} N$ superlattices J. Vac. Sci. Technol. A 11 (1993) 136

${ }^{8}$ A. Hörling, L. Hultman, M. Odén, J. Sjölén, L. Karlsson Thermal Stability of arc evaporated high aluminiumcontent $T_{1-x} A l_{x} N$ thin films J. Vac. Sci. Technol. A 20 (2002) 1815

${ }^{9}$ T. Ikeda, H. Satoh Phase formation and characterization of hard coatings in the Ti-Al-N system prepared by the cathodic arc ion plating method Thin Solid Films 195 (1991) 99-110

${ }^{10}$ H. Oettel, R. Wiedemann, S. Preisler, Surf. Coat. Technol. 74-75 (1995) 273

${ }^{11}$ C.V. Falub, A. Karimi, M. Ante, W. Kalss Interdependence between stress and texture in arc evaporated Ti-Al-N thin films Surf. Coat. Technol. 201 (2007) 5891

${ }^{12}$ I. Petrov, P.B. Barna, L. Hultman, J.E. Greene Microstructural evolution during film growth J. Vac. Sci. Technol. A 21 (2003) 117

${ }^{13}$ F. Adibi, I. Petrov, J.E. Greene, L. Hultman, J.-E. Sundgren Effects of high-flux low-energy (20-100 eV) ion irradiation during deposition on the microstructure and preferred orientation of $T_{0.5} A l_{0.5} \mathrm{~N}$ alloys grown by ultrahigh-vacuum reactive magnetron sputtering J. Appl. Phys. 73 (1993) 8580

${ }^{14}$ V. Kouznetsov, K. Macak, J.M. Schneider, U. Helmersson and I. Petrov, Surf. Coat. Technol. 122 (1999) 290

${ }^{15}$ J. Böhlmark, J. Alami, C. Christou, A.P. Ehiasarian, U. Helmersson Ionization of sputtered metals in high power pulsed magnetron sputtering J. Vac. Sci. Technol. A 23 (2005) 18

${ }^{16}$ G. Ehrlich and F.G. Hudda, J. Chem. Phys. 44 (1966) 1039

${ }^{17}$ G. Ehrlich, Surf. Sci. 331-333 (1995) 865

${ }^{18}$ B.W. Karr, D.G. Cahill, I. Petrov and J.E. Greene, Phys. Rev. B 61 (2000) 16137

${ }^{19}$ S. Kodambaka, V. Petrova, A. Vaillionis, I. Petrov, and J.E. Greene, Surf. Sci. 526 (2003) 85

${ }^{20}$ M. Lattemann et al., Thin Solid Films 518, 5978 (2010)

${ }^{21} \mathrm{http} / / /$ www.cemecon.de/coating_technology/2_coating_units/25_cc_800sup_sup_9_hipims/index_eng.html, accessed in April 2011

${ }^{22}$ G. Greczynski and L. Hultman Time and energy resolved ion mass spectroscopy studies of the ion flux during high power pulsed magnetron sputtering of $\mathrm{Cr}$ in $\mathrm{Ar}$ and $\mathrm{Ar} / \mathrm{N}_{2}$ atmospheres Vacuum 84 (2010) 1159-1170

${ }^{23}$ J. Jensen, D. Martin, A. Surpi, T. Kubart, Nucl. Instr. Meth. B 268 (2010) 1893

${ }^{24}$ see, e.g., chapter 6 in M. Birkholz Thin Film Analysis by X-ray Scattering, ISBN-10: 3-527-31052-5, Wiley-VCH, Weinheim 2006

${ }^{25}$ A.J. Wang, S.L. Shang, Y. Du, Y. Kong, L.J. Zhang, L. Chen, D.D. Zhao, Z.K. Liu Structural and elastic properties of cubic and hexagonal TiN and AlN from first-principles calculations Computational Materials Science 48 (2010) 705-709

${ }^{26}$ J. O. Kim, J. D. Achenbach, P. B. Mirkarimi, M. Shin and S. A. Barnet J. Appl. Phys. 72 (1992) 1805

${ }^{27} \mathrm{~V}$. Podgursky Ab initio calculations of elastic properties of isotropic and oriented $T i_{I_{-}} A l_{x} N$ hard coatings $\mathrm{J}$. Phys. D: Appl. Phys. 40 (2007) 4021-4026

${ }^{28}$ W. C. Oliver and G. M. Pharr, J. Mater. Res. 7 (1992) 1564 
${ }^{29}$ The JCPDS database (1998), data set number: 38-1420; W. Wong-Ng, H. McMurdie, B. Paretzkin, C. Hubbard, A. Dragoo, Powder Diffraction 2 (1987) 2

${ }^{30}$ P. H. Mayrhofer, D. Music, J. M. Schneider Ab initio calculated binodal and spinodal of cubic $T i_{1-x} A l_{x} N$ Appl. Phys. Lett. 88 (2006) 071922

${ }^{31}$ B. Alling, A. Karimi, I.A. Abrikosov Electronic origin of the isostructural decomposition in cubic $M_{1-x} A l_{x} N$ $(M=T i, C r, S c, H f)$ : A first-principles study Surf. Coat. Technol. 203 (2008) 883

${ }^{32}$ G. Greczynski, J. Lu, M. Johansson, J. Jensen, I. Petrov, J.E. Greene, and L. Hultman Selection of metal ion irradiation for controlling $T i_{I_{-x}} A l_{x} N$ alloy growth via hybrid HIPIMS/magnetron co-sputtering, submitted

${ }^{33}$ I. Petrov, L. Hultman, U. Helmersson, J. E. Sundgren, J. E. Greene, Microstructure Modification of TiN by Ion Bombardment during Reactive Sputter Deposition, Thin Solid Films, 169299 (1989)

${ }^{34}$ T. Suzuki, Y. Makino, M. Samandi, S. Miyake Microstructure and secular instability of the $\left(\operatorname{Ti}_{l_{-x}} A l_{x}\right) N$ films prepared by ion-beam-assisted-deposition J. Mater. Sci. 35 (2000) 4193

${ }^{35}$ P.H. Mayrhofer, H. Clemens, C. Mitterer Interfaces in nanostructured thin films and their influence on hardness Z. Metallk. 96 (2005) 468-80

${ }^{36}$ A. Guillaumot, F. Lapostolle, C. Langlade, A. Billard, J. C. Oliveira, A. Cavaleiro, and C. Dublanche-Tixier Influence of Substrate Biasing on (Al, Ti)N Thin Films Deposited by a Hybrid HiPIMS/DC Sputtering Process IEEE Transactions on Plasma Sci. 38 (2010) 3040

${ }^{37}$ I. Yonenaga, T. Shima, H.F.S Marcel Nanoindentation hardness and elastic moduli of bulk single-crystal AlN Jap. J. Appl. Phys. 41 (2002) 4620-1 